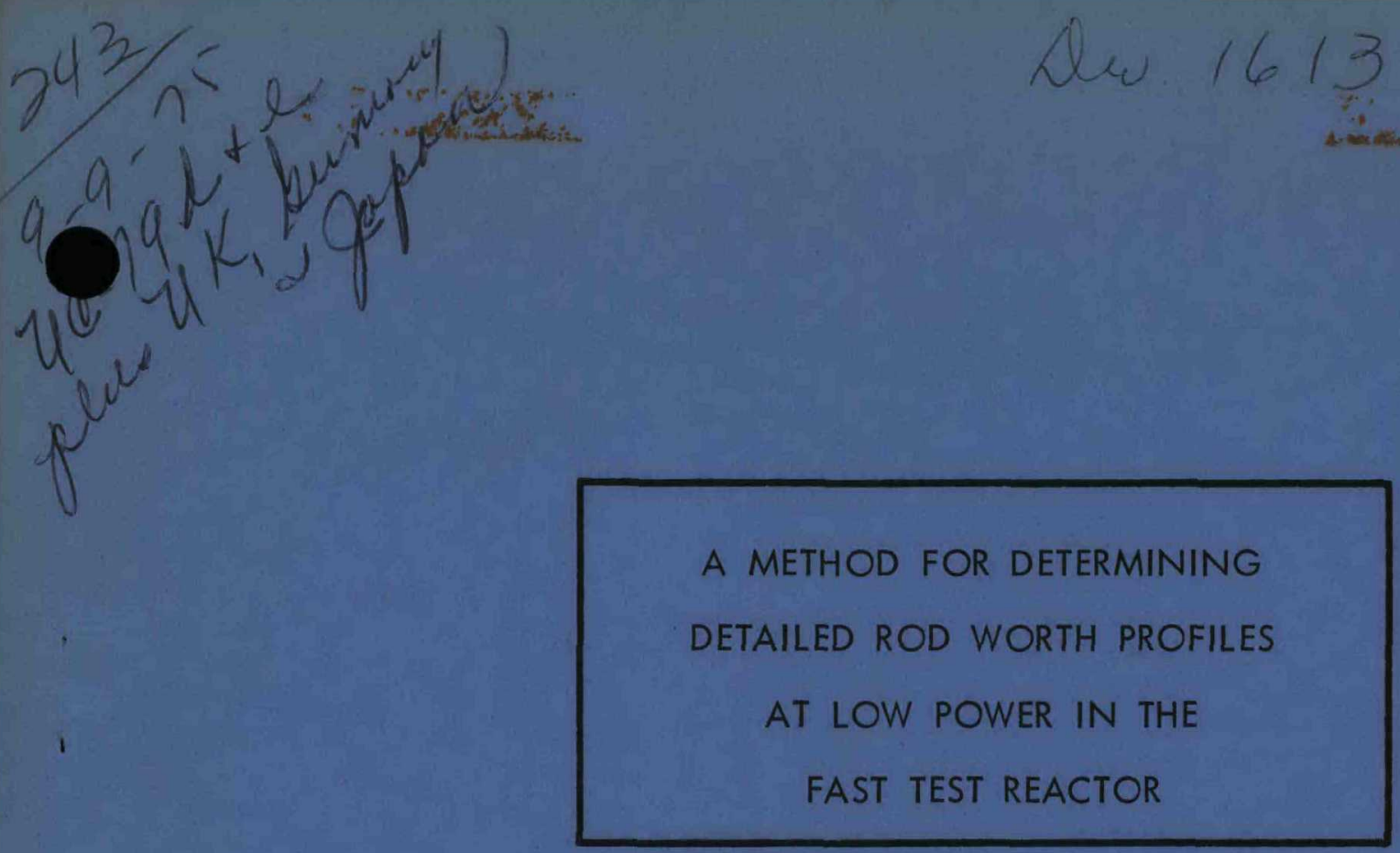

HEDL TME 75-79

UC $79 \mathrm{~d}, \mathrm{e}$

\begin{abstract}
AT LOW POWER IN THE
FAST TEST REACTOR
\end{abstract}

HANFORD ENGINEERING DEVELOPMENT LABORATORY

Operated by Westinghouse Hanford Company

A Subsidiary of Westinghouse Electric Corporation

Prepared for the U.S. Energy Research and Development

Administration under Contract No. AT(45-1)-2170

P.O. Box 1970 Richland, WA 99352

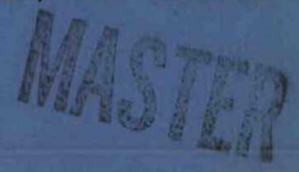




\section{DISCLAIMER}

This report was prepared as an account of work sponsored by an agency of the United States Government. Neither the United States Government nor any agency Thereof, nor any of their employees, makes any warranty, express or implied, or assumes any legal liability or responsibility for the accuracy, completeness, or usefulness of any information, apparatus, product, or process disclosed, or represents that its use would not infringe privately owned rights. Reference herein to any specific commercial product, process, or service by trade name, trademark, manufacturer, or otherwise does not necessarily constitute or imply its endorsement, recommendation, or favoring by the United States Government or any agency thereof. The views and opinions of authors expressed herein do not necessarily state or reflect those of the United States Government or any agency thereof. 


\section{DISCLAIMER}

Portions of this document may be illegible in electronic image products. Images are produced from the best available original document. 


\section{NOTICE}

This report was prepared as an account of work sponsored by the United States Government. Neither the United States nor the U.S. ERDA, nor any of their employees, nor any of their contractors, subcontractors, or their employees, makes any warranty, express or implied, or assumes any legal liability or responsibility for the accuracy, completeness or usefulness of any information, apparatus, product or process disclosed, or represents that its use would not infringe privately owned rights.

Printed in the United States of America

$$
\text { Available from }
$$

National Technical Information Service

U.S. Department of Commerce 5285 Port Royal Road

Springfield, Virginia 22161

Price: Printed Copy $\$ 4.00$; Microfiche $\$ 2.25$ 
HEDL TME 75-79

UC $79 d, e$

\section{A METHOD FOR DETERMINING}

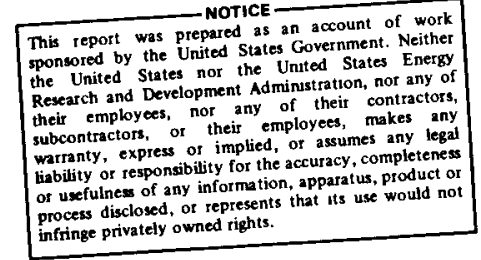

DETAILED ROD WORTH PROFILES

AT LOW POWER IN THE

FAST TEST REACTOR

by

R. A. Sevenich

August 1975

\begin{tabular}{|c|c|c|}
\hline $\begin{array}{l}\text { Operated by the } \\
\text { Westinghouse } \\
\text { Hanford Company }\end{array}$ & $\begin{array}{l}\text { A Subsidiary of } \\
\text { Westinghouse Electric } \\
\text { Corporation }\end{array}$ & $\begin{array}{l}\text { Tor the United States } \\
\text { Energy Research and } \\
\text { Development Administration } \\
\text { Contract No.AT/45.121770 }\end{array}$ \\
\hline
\end{tabular}


$\bullet$

•

- 
HEDL TME 75-79

UC $79 \mathrm{~d}, \mathrm{e}$

\title{
A METHOD FOR DETERMINING DETAILED ROD WORTH PROFILES AT LOW POWER IN THE FAST TEST REACTOR
}

\author{
R. A. Sevenich
}

\section{ABSTRACT}

A method for obtaining a detailed rod worth profile at low power for a slow control rod insertion is presented. The accuracy of the method depends on a preparatory experiment in which the test rod is dropped quickly to yield, upon analysis, the magnitude of the rod worth and an effective source value. These numbers are employed to initialize the inverse kinetics analysis for the slow insertion. Corrections for changes in detection efficiency are not included for the simulated experiments. 
-

,

- 


\section{CONTENTS}

PAGE NO.

1. INTRODUCTION

1

2. DESCRIPTION OF CALCULATIONAL MODEL 2

2.1 INVERSE KINETICS 2

2.2 IKRD SIMULATION 3

2.3 IKRRI SIMULATION

3. RESULTS OF SIMULATIONS

3.1 IKRD RESULTS

3.2 IKRRI RESULTS 9

3.3 UNCERTAINTY ASSESSMENT FOR IKRRI RESULTS 11

4. CONCLUSIONS 15

REFERENCES 16

$\begin{array}{ll}\text { APPENDIX A A-1-6 } & \end{array}$

APPENDIX B $B-1-11$

APPENDIX C C $\quad$ - $1-8$ 


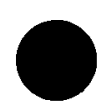

- 


\section{FIGURES}

Figure No.

1 IKRD Simulation Flow Chart

Page No.

2 IKRRI Simulation Flow Chart

3 Relative Reactivity as a Function of Relative

Rod Insertion for IKRRI Simulation Input

4 Logic Diagram for IKRRI Experiment with Estimate of Uncertainty in Rod Worth Profile

$5 \quad$ Uncertainty Envelope for Output Reactivity Profile from IKRRI Simulation

\section{$\underline{\text { TABLES }}$}

Table No.

Page No.

I Inferred Reactivities from Three Independent Detectors Compared to Input Reactivities for an IKRD Simulation

II Inferred Reactivities with Estimated Standard Deviations for a Thirty Detector IKRD Simulation

III IKRRI Results Output Reactivity Profile Averaged from Three Independent Detectors 


\section{INTRODUCTION}

An evaluation has been made of the possibility of employing an $i$ kinetics technique to obtain accurate control rod calibration curves the Fast Test Reactor (FTR) of the Fast Flux Test Facility (FFTF). T investigation is based on the analys is of simulated low-power reactor periments. The proposed method is akin to inverse kinetics rod drop (IKRD) with the important distinction that in this method the control slowly inserted into the reactor rather than dropped. It is convenie use the acronym, IKRRI (inverse kinetics rod run-in) for this slow in experiment.

In its present form the IKRRI analysis assumes that changes in $d$ tion efficiency are insignificant. Future work incorporating a corre for such efficiency changes in situations where they are important wi hopefully generalize this method and make its usefulness more universi

It is illuminating to compare IKRRI to IKRD. The latter relies rapid rod insertion for an accurate value of total rod reactivity, wh the IKRRI technique requires the slower rod insertion to uncover the of the worth profile. The accuracy of IKRD experiments in the absenc significant detection efficiency changes has been firmly established ( It has been suggested that the relative inaccuracy of the IKRRI analy might be ameliorated by initializing the IKRRI experiment by a prepar IKRD experiment ${ }^{(5)}$. This report shows that expectation to be justifi

This method can be used for calibration of control rods in the $F$ reactor if the Low Level Flux Monitor (LLFM) positions have only smal detection efficiency changes. Preliminary indications ${ }^{(5)}$ suggest tha will be the case for the two LLFM locations in trisectors other than corresponding to the test rod position. Data from even the third LLFI position can be employed for reactivity insertions of small enough ma so that the detection efficiency changes are insignificant. 


\section{DESCRIPTION OF CALCULATIONAL MODEL}

\subsection{Inverse Kinetics}

The inverse kinetics analyses discussed here are rooted in the point reactor equations,

$$
\begin{aligned}
& \frac{d n}{d t}=(\rho-\beta) \frac{n}{\Lambda}+\sum_{i} \lambda_{i} c_{i}+q \\
& \frac{d c_{i}}{d t}=\beta_{i} \frac{n}{\Lambda}-\lambda_{i} c_{i},
\end{aligned}
$$

where $n=$ average number of neutrons/volume

$t=$ time

$\rho=$ reactivity

$\Lambda=$ prompt neutron generation time

$c_{i}=$ number/volume of type $i$ precursors

$\beta_{i}=$ fraction of neutrons from precursor type $i$

$q=$ source term

$\beta=\sum_{i} \beta_{i}$.

Six precursor groups are usually adequate so that the index $i$ runs from 1 to 6. The point reactor equations are, of course, approximate. In particular, there is no mention of the spatial dependence of the parameters involved. A careful derivation of these equations from transport theory indicates the precise nature of the approximations involved $(6,7)$. For the purposes of this discussion it is sufficient to note that the equations are useful when the reactor is near critical with no large localized perturbations in the flux shape.

Inverse kinetics solves these equations for $\rho(t)$ after relating $n(t)$ to the count rate from the neutron detectors. If $q$ is known, the equations are quite simply coded for computer calculation. However, $q$ is typically unknown and the solution for $\rho(t)$ is less straightforward. In the method developed by Cohn $(1)$ the reactivity for times after rod motion had stopped was fitted to the function $A+B f(t)$. Arguing that the reactivity must be constant after 
the cessation of rod motion, a search was made for a source value yielding

$B=0$. A conceptually similar approach was advanced by Yang and Albrecht ${ }^{(4)}$. Their scheme involved solving the point reactor equations for the source term and fitting it to a curve $a+b z(t)$. Because the source term is constant over the time period of the experiment, a minimization scheme is applied to $b$ by finding the value of final reactivity giving $b=0$.

In principle, codes such as the Cohn or Yang-Albrecht algorithms could be used whether the rod is inserted quickly or slowly. However, in both algorithms the minimization and search schemes are based on the count rate data after rod motion has stopped. In the case of a slow rod insertion these late data are at such a low count rate that the noise level seriously interferes with the minimization and search schemes. As mentioned in the introduction, this difficulty can be partly overcome by using an IKRD experiment to find an accurate source value and then performing the IKRRI experiment. When done in this fashion the inverse kinetics code needs no minimization and search capability because the source value is now known.

\subsection{IKRD Simulation}

For simulation of either IKRD or IKRRI experiments, count rate data characteristic of the reactivity insertion must be simulated. Such data were prepared for these applications by use of a direct kinetics subroutine. A derivation of such an algorithm from the point reactor equations appears in Appendix A. Detection noise to be superimposed on the data was constructed employing the pseudo random number generating function called RANF, available as a FORTRAN function. RANF yields pseudo random numbers distributed uniformly on the interval 0 to 1 . These numbers were then converted to a Gaussian distribution characteristic of the nuclear counting statistics.

Figure 1 presents a flow chart for the IKRD simulation. The 'input' parameters include an effective source value, the initial reactivity characterizing the slightly subcritical equilibrium state of the reactor before the rod drop, and the final reactivity after the drop. In an actual experiment the degree of initial subcriticality is chosen to maximize the detector countrate without exceeding the dynamic range of the detection system and 


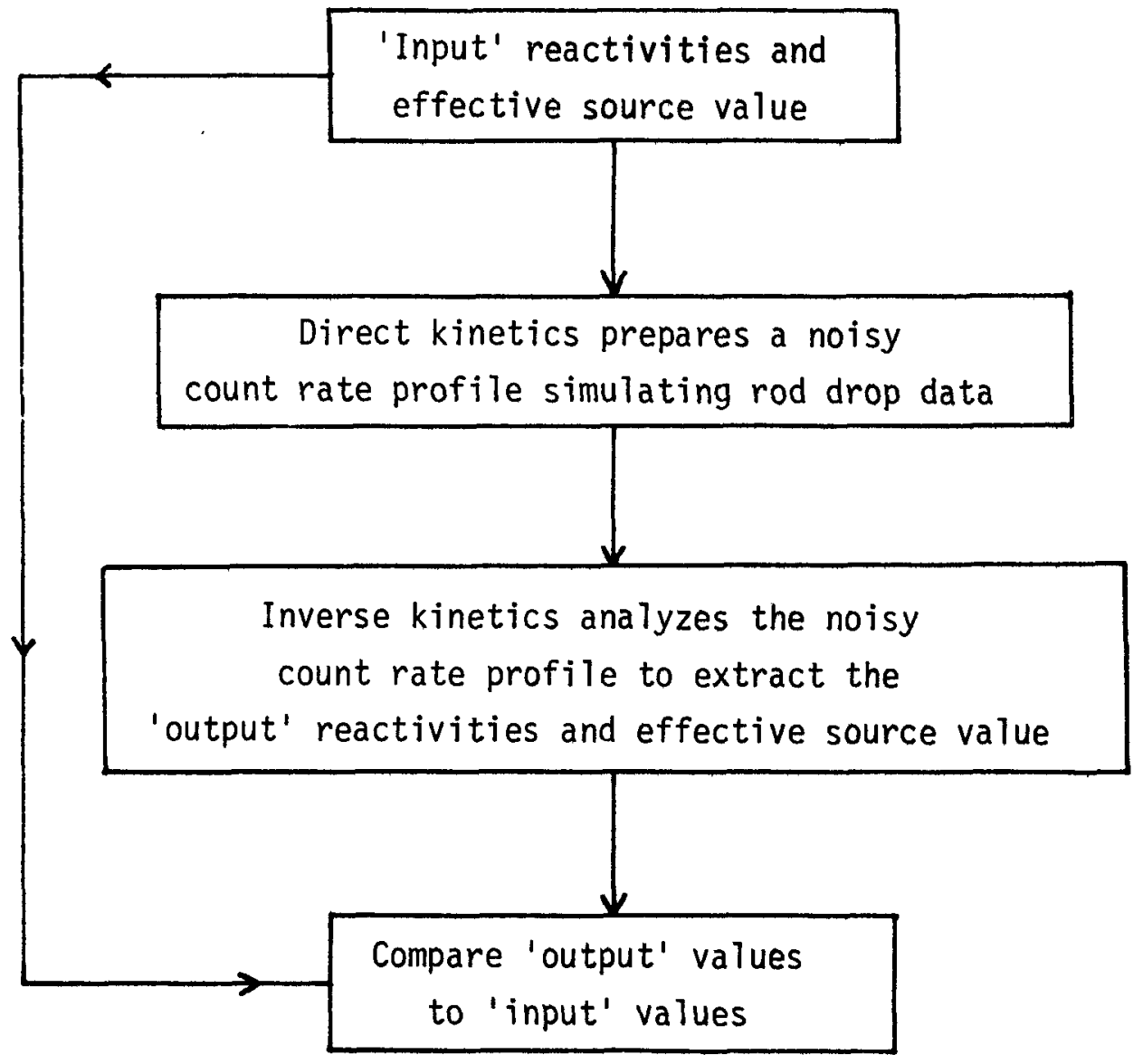

Figure 1. IKRD Simulation Flow Chart. 
without introducing significant counting losses. Such a choice lessens the effect of detection noise. The direct kinetics subroutine employs the input parameters to generate the corresponding noisy count rate profile. The inverse kinetics code then analyzes this simulated profile yielding as 'output' parameters the initial reactivity, the final reactivity, and an effective source value. Comparison of the input to the output parameters completes the IKRD simulation.

A derivation of the inverse kinetics code is available elsewhere ${ }^{(8)}$ and is not presented here. The code chosen is the Yang-Albrecht algorithm because of its demonstrated lack of bias. A Fortran listing of the code appears in Appendix B.

\subsection{IKRRI Simulation}

Figure 2 is a flow chart for the IKRRI simulation. The input reactivity profile is of the form

$$
\rho=A x+B x^{2}+C x^{3}
$$

where $A, B$, and $C$ are coefficients and $x$ is the distance the rod is inserted into the reactor. It is assumed that the test rod is inserted at a constant speed so that $x$ varies linearly with time. If $\rho$ is normalized to the net worth of the rod and if $x$ is normalized to the full insertion length then both $\rho$ and $x$ vary from 0 to 1 as the rod is inserted. This convenient normalization would therefore require that $A+B+C=1$. Figure 3 displays the $\rho(x)$ dependence chosen for the simulation. This dependence is used to drive the direct kinetics subroutine which generates the simulated count rate data. These data are then analyzed with inverse kinetics. Note that the inverse kinetics code has available to it the effective source value gleaned from the IKRD experiment. Consequently the inverse kinetics employed in the IKRRI experiment is simpler than that needed for the IKRD analysis. This simpler inverse kinetics algorithm is derived in Appendix $A$. The reactivity values inferred by inverse kinetics are then fit to the functional form

$$
\rho=A^{\prime} x+B^{\prime} x^{2}+C^{\prime} x^{3}+D^{\prime} x^{4} \text {. }
$$




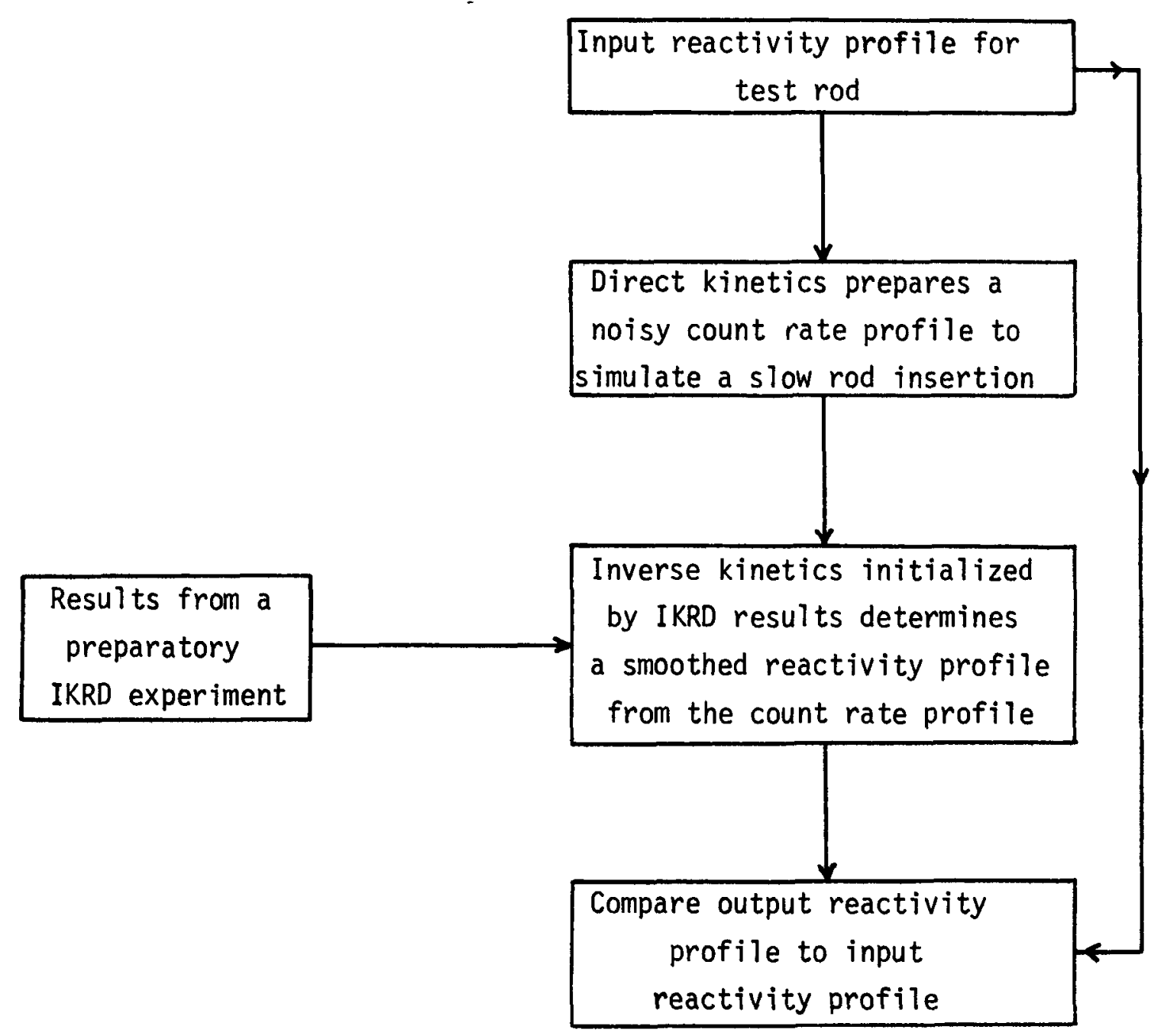

Figure 2. IKRRI Simulation Flow Chart. 


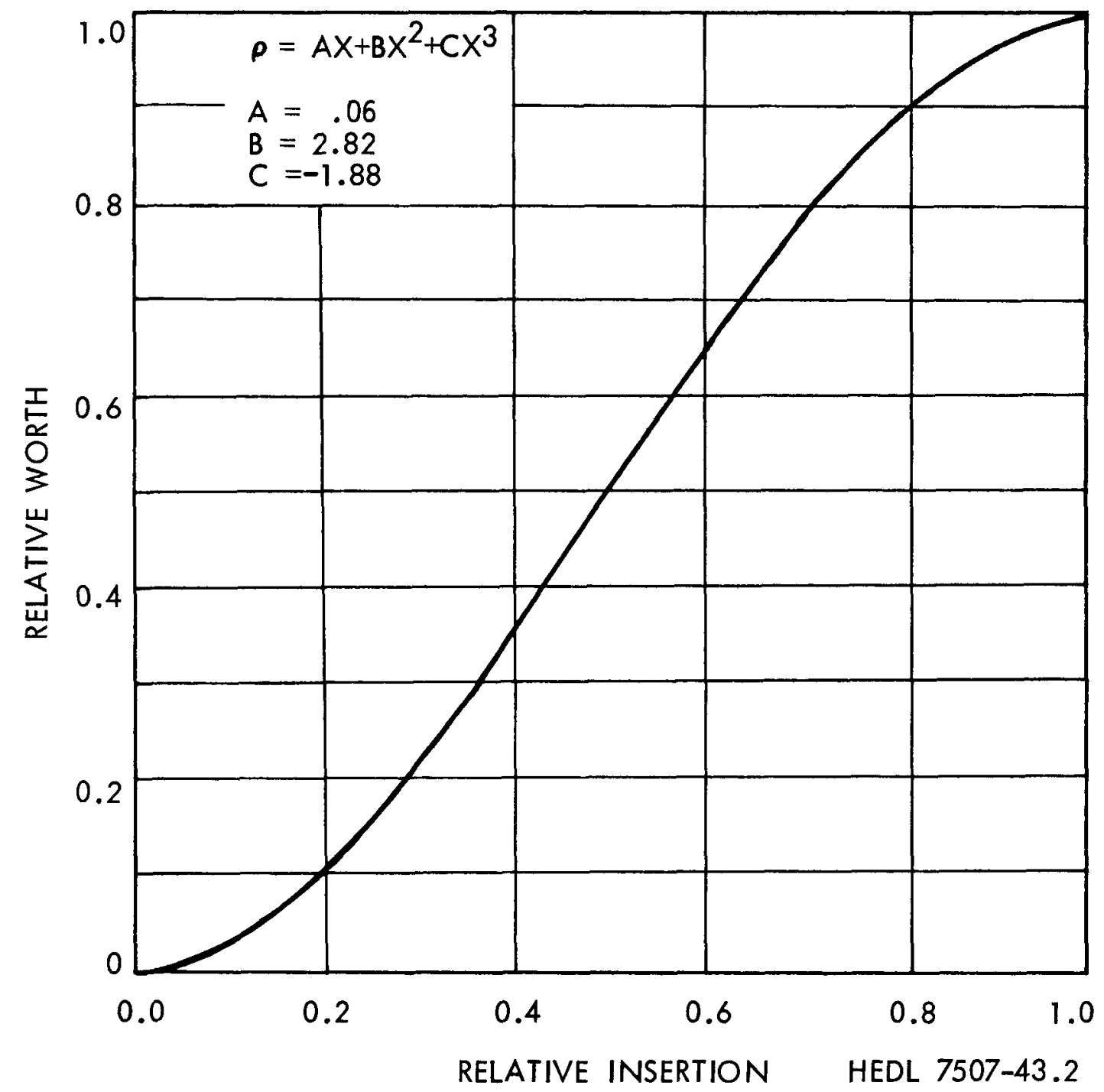

Figure 3. Relative Reactivity as a Function of Relative Rod Insertion for IKRRI Simulation Input 
In the absence of noise on the simulated data one finds

$$
A^{\prime} \approx A, B^{i} \approx B, C^{\prime} \approx C \text {, and } D^{\prime} \approx 0 \text {. }
$$

In the presence of noise such close matching of input to output reactivity coefficients does not occur, but the point-by-point comparison of the inputto-output reactivity profiles is favorable.

\section{RESULTS OF SIMULATIONS}

\subsection{IKRD Results}

A Fortran listing of the Yang-Albrecht code employed for IKRD analysis appears in Appendix B. To exploit the advantages of statistics it would be desirable to measure the test rod with a high number of rod drop experiments. Because of the high value of reactor time this is not possible in practice. If detection noise is the principal cause of drop-to-drop variation then the use of several independent detection systems can partly alleviate the need for a large number of drops. FTR, for example, has three independent low level detection systems and one rod drop results in three count rate profiles with independent detection noise statistics.

Table I presents results for the simulated analys is of count rate profiles from three detectors looking at the same rod drop.

\section{Table I}

Inferred Reactivities from Three Independent Detectors Compared to Input Reactivities for an IKRD Simulation

\begin{tabular}{lccccc}
\cline { 2 - 3 } & $\begin{array}{c}\text { Input to } \\
\text { Direct } \\
\text { Kinetics }\end{array}$ & $\begin{array}{c}\text { Inferred } \\
\text { from } \\
\text { Detector 1 }\end{array}$ & $\begin{array}{c}\text { Inferred } \\
\text { from } \\
\text { Detector 2 }\end{array}$ & $\begin{array}{c}\text { Inferred } \\
\text { from } \\
\text { Detector 3 }\end{array}$ & $\begin{array}{c}\text { Average from } \\
\text { all 3 Detectors }\end{array}$ \\
\hline $\begin{array}{c}\text { Initial } \\
\text { Reac- } \\
\text { tivity }\end{array}$ & $-.01 \$$ & $-.00991 \$$ & $-.010005 \$$ & $-.010002 \$$ & $-.00997 \$$ \\
$\begin{array}{l}\text { Final } \\
\text { Reac- } \\
\text { tivity }\end{array}$ & $-3.95 \$$ & $-3.941 \$$ & $-3.946 \$$ & $-3.942 \$$ & $-3.943 \$$
\end{tabular}


To examine the statistical spread to be expected in such simulations a computer run for thirty such detectors was made. The results appear in Table II with the estimated standard deviations for the initial and final reactivities. In both Tables I and II the input reactivity to the direct kinetics subroutine is presented so comparisons can be made. The accuracy of the results is enchanced as the initial count rate is made larger. On the other hand, if the initial count rate is too high it may exceed the range of the detection system or get into a region where counting losses become significant. For this analysis the initial count rate at one cent subcritical was taken to be approximately $2.6 \times 10^{5} \mathrm{cps}$.

\section{Table II}

Inferred Reactivities with Estimated Standard Deviations for a Thirty Detector IKRD Simulation Input to Average from 30 Detectors Direct Kinetics with Estimated Standard Deviation

Initial

Reac-

tivity

Final

Reactivity
$-.0100 \$$

$-3.9500 \$$
$-.009995 \$(1 \sigma=.000035 \$)$

$-3.9476 \$(1 \sigma=.0056 \$)$

\subsection{IKRRI Results}

A Fortran listing of the IKRRI analysis appears in Appendix C. The direct kinetics code is driven by a reactivity dependence

$$
\rho_{\text {in }}=A x+B x^{2}+C x^{3}
$$

$$
\text { where } \begin{aligned}
A & =.06, \\
B & =2.82, \text { and } \\
C & =-1.88 .
\end{aligned}
$$


Detection noise is then superimposed on the simulated count rate data. The inverse kinetics code, initialized-by the IKRD experiment, then infers a reactivity versus time profile which is converted to a reactivity versus rod length inserted profile. The latter profile is then fitted in a least squares manner to the dependence

$$
\rho_{\text {out }}=A^{\prime} x+B^{\prime} x^{2}+C^{\prime} x^{3}+D^{\prime} x^{4} \text {. }
$$

The 4th order dependence allows for sufficient detail in the reactivity profile. In an actual measurement $\rho_{\text {in }}$ would be unknown so that choice of a $3 r d$ order dependence for $\rho_{\text {out }}$ was not made, to avoid deceptively good results.

To assess the ability of the code to extract the $\rho(x)$ dependence a noisefree simulation was carried out and yielded

$$
\begin{aligned}
& A^{\prime}=.0607 \\
& B^{\prime}=2.8185 \\
& C^{\prime}=-1.8758, \text { and } \\
& D^{\prime}=-.003437
\end{aligned}
$$

matching the input $A, B$, and $C$ rather well.

With detection noise present the match of the pout coefficients to the $\rho_{\text {in }}$ coefficients suffers, but a point-by-point comparison of the $\rho_{\text {out }}$ and $\rho_{\text {in }}$ profiles still shows excellent agreement. Such a comparison is shown in Table III. Note that all entries in that table are dimensionless. The fractional differences at various points between the $\rho_{\text {out }}$ and $\rho_{\text {in }}$ profile appear in the third column. All the fractional differences are quite small. Incidentally, the extremely small fractional difference at the end of the table results from the constraint on the fitting routine that the relative rod worth be unity when the relative rod insertion reaches unity. Thus the IKRRI analysis is quite reasonable for extracting the reactivity profile in the presence of noise on the count rate data. 
Table III

IKRRI Results

Output Reactivity Profile

Averaged from Three Independent Detectors

\begin{tabular}{|c|c|c|c|}
\hline $\begin{array}{l}\text { Input Relative } \\
\text { eactivity Profile }\end{array}$ & $\begin{array}{c}\text { Output Relative } \\
\text { Reactivity Profile }\end{array}$ & $\begin{array}{l}\text { Fractional } \\
\text { Difference } \\
\end{array}$ & $\begin{array}{l}\text { Relative Rod } \\
\text { Insertion }\end{array}$ \\
\hline $\begin{array}{l}.2312963-02 \\
.133459 \mathrm{E}-01 \\
.323200 \mathrm{E}-01 \\
.585133 \mathrm{E}-01 \\
.912038 \mathrm{E}-01 \\
.129670 \mathrm{E}+00 \\
.173189 \mathrm{E}+00 \\
.221040 \mathrm{E}+00 \\
.272500 \mathrm{E}+00 \\
.326849 \mathrm{E}+00 \\
.383363 \mathrm{E}+00 \\
.441320 \mathrm{E}+00 \\
.500000 \mathrm{E}+00 \\
.558680 \mathrm{E}+00 \\
.616637 \mathrm{E}+00 \\
.673751 \mathrm{E}+00 \\
.727500 \mathrm{E}+00 \\
.778960 \mathrm{E}+00 \\
.826811 \mathrm{E}+00 \\
.870330 \mathrm{E}+00 \\
.908796 \mathrm{E}+00 \\
.941487 \mathrm{E}+00 \\
.967680 \mathrm{E}+00 \\
.986654 \mathrm{E}+00 \\
.997687 \mathrm{E}+00 \\
.100000 \mathrm{E}+01\end{array}$ & $\begin{array}{l}.238822 \mathrm{E}-02 \\
.134954 \mathrm{E}-01 \\
.324736 \mathrm{E}-01 \\
.586349 \mathrm{E}-01 \\
.912865 \mathrm{E}-01 \\
.129731 \mathrm{E}+00 \\
.173266 \mathrm{E}+00 \\
.221186 \mathrm{E}+00 \\
.272777 \mathrm{E}+00 \\
.327324 \mathrm{E}+00 \\
.384105 \mathrm{E}+00 \\
.442395 \mathrm{E}+00 \\
.501463 \mathrm{E}+00 \\
.560574 \mathrm{E}+00 \\
.618987 \mathrm{E}+00 \\
.675957 \mathrm{E}+00 \\
.730736 \mathrm{E}+00 \\
.782568 \mathrm{E}+00 \\
.830695 \mathrm{E}+00 \\
.874353 \mathrm{E}+00 \\
.912773 \mathrm{E}+00 \\
.945182 \mathrm{E}+00 \\
.970802 \mathrm{E}+00 \\
.988850 \mathrm{E}+00 \\
.998538 \mathrm{E}+00 \\
.100000 \mathrm{E}+01\end{array}$ & $\begin{array}{l}-.325396 \mathrm{E}-01 \\
-.111977 \mathrm{E}-01 \\
-.475160 \mathrm{E}-02 \\
-.207802 \mathrm{E}-02 \\
-.906813 \mathrm{E}-03 \\
-.473305 \mathrm{E}-03 \\
-.446443 \mathrm{E}-03 \\
-.658358 \mathrm{E}-03 \\
-.101368 \mathrm{E}-02 \\
-.145306 \mathrm{E}-02 \\
-.193654 \mathrm{E}-02 \\
-.243507 \mathrm{E}-02 \\
-.292591 \mathrm{E}-02 \\
-.338990 \mathrm{E}-02 \\
-.380966 \mathrm{E}-02 \\
-.416838 \mathrm{E}-02 \\
-.444880 \mathrm{E}-02 \\
-.463235 \mathrm{E}-02 \\
-.469819 \mathrm{E}-02 \\
-.462229 \mathrm{E}-02 \\
-.437609 \mathrm{E}-02 \\
-.392495 \mathrm{E}-02 \\
-.322603 \mathrm{E}-02 \\
-.222521 \mathrm{E}-02 \\
-.852922 \mathrm{E}-03 \\
-.142109 \mathrm{E}-13\end{array}$ & $\begin{array}{l}.200000 \mathrm{E}-01 \\
.600000 \mathrm{E}-01 \\
.100000 \mathrm{E}+00 \\
.140000 \mathrm{E}+00 \\
.180000 \mathrm{E}+00 \\
.220000 \mathrm{E}+00 \\
.260000 \mathrm{E}+00 \\
.300000 \mathrm{E}+00 \\
.340000 \mathrm{E}+00 \\
.380000 \mathrm{E}+00 \\
.42000 \mathrm{E}+00 \\
.460000 \mathrm{E}+00 \\
.500000 \mathrm{E}+00 \\
.540000 \mathrm{E}+00 \\
.580000 \mathrm{E}+00 \\
.620000 \mathrm{E}+00 \\
.660000 \mathrm{E}+00 \\
.700000 \mathrm{E}+00 \\
.740000 \mathrm{E}+00 \\
.780000 \mathrm{E}+00 \\
.820000 \mathrm{E}+00 \\
.860000 \mathrm{E}+00 \\
.900000 \mathrm{E}+00 \\
.940000 \mathrm{E}+00 \\
.980000 \mathrm{E}+00 \\
.100000 \mathrm{E}+01\end{array}$ \\
\hline
\end{tabular}

\subsection{Uncertainty Assessment for IKRRI Results}

It is desirable to obtain good estimates for the uncertainty in the rod worth profile resulting from the IKRRI analysis. Classical propagation-oferror techniques have been successfully applied to IKRD experiments analyzed with the 'three-point method ${ }^{(9)}$.' However, an IKRRI experiment corresponds to a reactivity which varies slowly with time and the inverse kinetics do not yield a simple closed form for the dependence of inferred reactivity on the 
observed count rate. This lack of simplicity is compounded by the fact that the statistical error in count rate values changes with the count rate as the rod is inserted. For these reasons a classical propagation-of-error analys is becomes intractable for an IKRRI measurement. Consequently, an intuitively equivalent scheme of error analysis has been devised to estimate uncertainties. This method would employ data from an experimental rod run-in to construct many quantitatively equivalent simulations from which estimates of standard deviations in the reactivities are calculated. It should be emphasized that these multiple simulations do not correspond to multiple experiments but rather are constructed from information generated by a single rod run-in experiment.

Figure 4 is a logic diagram of this uncertainty estimation scheme for a situation in which the rod run-in is observed by three independent detection systems. Figure 5 displays the uncertainty band corresponding to the $\rho_{\text {out }}(x)$ discussed in Section 3.2 of this report. The uncertainty band is the $\pm 2 \sigma(x)$ envelope about $\rho_{\text {out }}(x)$ where $\sigma(x)$ is the estimated standard deviation of $\rho_{\text {out }}(x)$. The listing of the IKRRI code in Appendix $C$ includes this uncertainty analysis. The coefficients $A, B, C$, and $D$ are found from each of the detector count rate profiles. Each of the three coefficient sets is then used to create a population sample of noisy count rate profiles. Next a reactivity profile is calculated from each count rate profile via inverse kinetics. The resulting set of reactivity profiles provides a basis for calculating estimates for the standard deviations for each reactivity point on the rod worth curve. As mentioned in Section 3.2, the rod worth curve itself is constructed using the average $A, B, C$, and $D$ values from the three coefficient sets from the three detectors. 


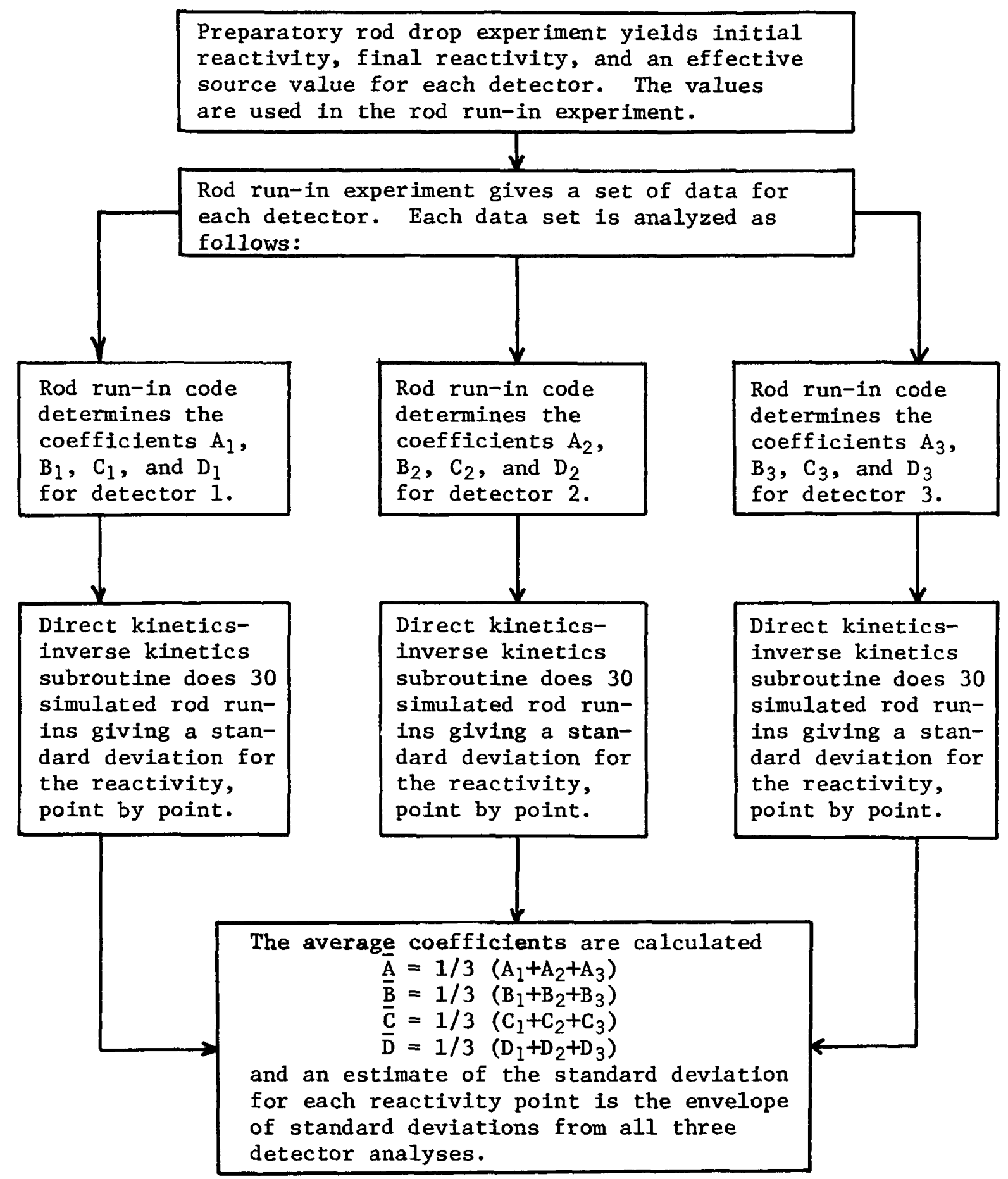

Figure 4. Logic Diagram for IKRRI Experiment with Estimate of Uncertainty in Rod Worth Profile. 


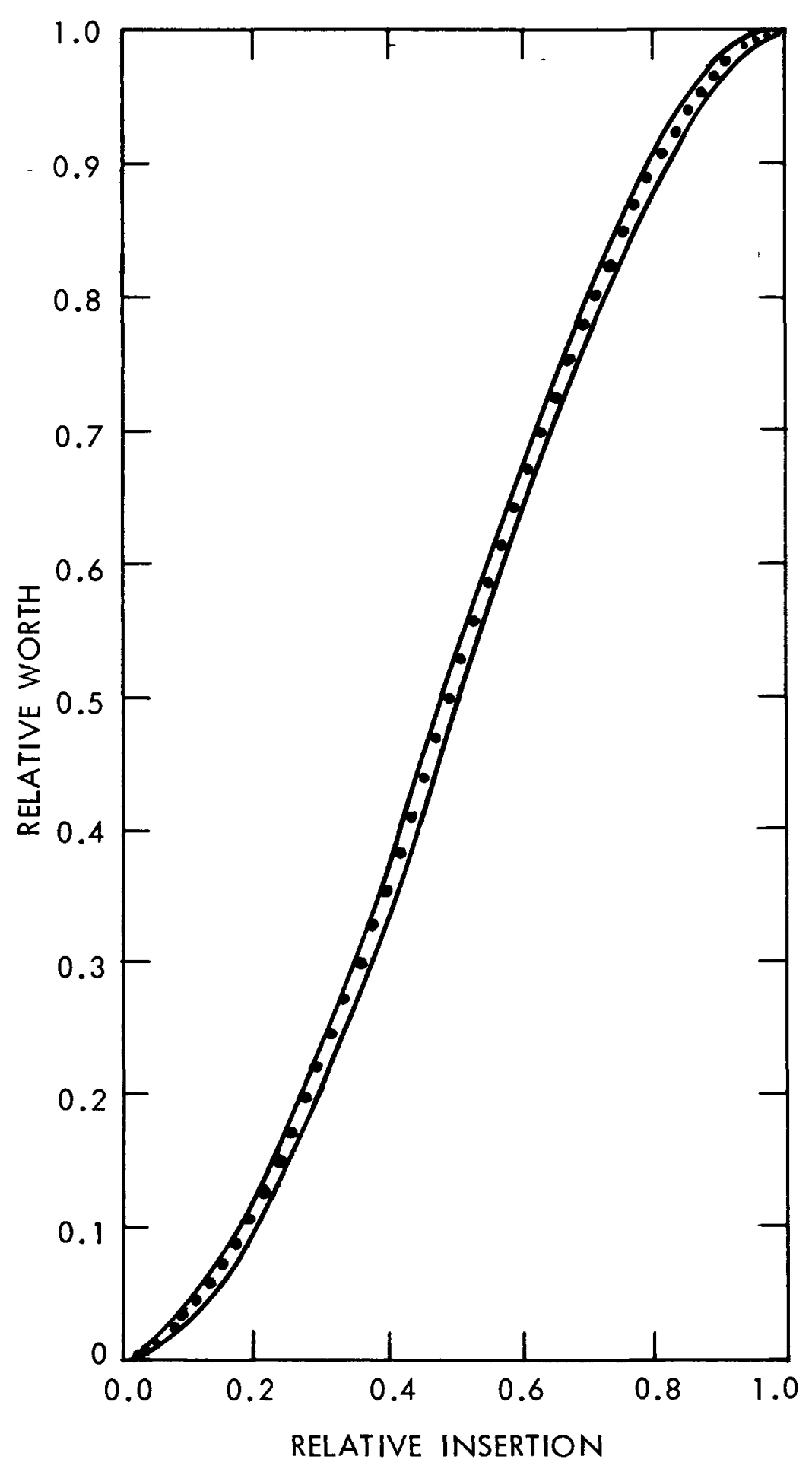

HEDL $7507-43.1$

Figure 5. Uncertainty Envelope for Output Reactivity Profile from IKRRI Simulation 


\section{CONCLUSIONS}

The IKRRI technique discussed in this report is capable of recovering reactivity profile detail from noisy count rate data. It must be recalled that in its present form it cannot handle significant changes in detection efficiency. However, corrections for such changes are under study and it may be feasible to incorporate such modifications into the technique. The relatively high accuracy of the IKRRI technique is a direct result of the suggestion $^{(5)}$ that the inverse kinetics be initialized by a preparatory IKRD experiment. 


\section{REFERENCES}

1. C.E. Cohn, "Experience with Subcriticality Determination by Rod Drop in the FTR-3 Critical Experiments," Trans. Am. Nucl. Soc., 14, 29, 1971.

2. S.G. Carpenter and R.W. Goin, "Rod-Drop Measurements of Subcriticality," Applied Physics Division Annual Report, July 1, 1969 to June 30, 1970, ANL-7710, pp. 206-209.

3. D.H. Shaftman, "Estimation of Degree of Subcriticality of ZPR FastCriticals Configurations by Methods of Neutron Source Multiplication", Argonne Nationa1 Laboratory, ZPR-TM-102, Apri1 1972.

4. C.Y. Yang and R.W. Albrecht, "Subcriticality Determination by a Novel Inverse Kinetics Technique," Trans. Am. Nuc1. Soc., 16, 297, 1973.

5. R.M. Fleischman, J.W. Upton, Jr., and R.A. Bennett, "Subcritical Reactivity Surveillance Procedures for the Fast Flux Test Facility," HEDL-TME 73-43, May 1973.

6. G.I. Bell and S. Glasstone, "Nuclear Reactor Theory," Van Nostrand Reinhold Co., Ch. 9, 1970.

7. D.L. Hetrick, "Dynamics of Nuclear Reactors," Univ. of Chicago Press, Chs. 1 and 8, 1971.

8. C.Y. Yang and R.W. Albrecht, "Inverse Kinetics Determination of Subcriticality," Nucl. Technol. 22, 323, 1974.

9. J.W. Allen, J.C. Robinson, and N.J. Ackermann, Jr., "Statistical Errors in Subcritical Reactivity Inferred from Inverse Kinetics Rod Drop Measurements Using the Three-Point Method," Nucl. Technol. 22, 315, 1974. 


\section{APPENDIX A \\ Derivation of Direct Kinetics Equations and Derivation of Inverse Kinetics \\ Equations With known Source}

The point reactor equations previously mentioned in Section 2.1 are

$$
\frac{d n}{d t}=(\rho-\beta) \frac{n}{\Lambda}+\sum \lambda_{i} c_{i}+q
$$

and

$$
\frac{d c_{i}}{d t}=\beta_{i} \frac{n}{\Lambda}-\lambda_{i} c_{i}, i=1, \ldots, 6 .
$$

Let $N(t)$ be the number of counts during a time interval $\Delta t$ ending at $t$. The efficiency $\varepsilon(t)$ can be defined by

$$
N(t)=\varepsilon(t) \frac{n(t)}{\Lambda} \text {. }
$$

Our assumption of constant detection efficiency allows us to rewrite this as

$$
N(t)=\frac{1}{\alpha} n(t)
$$

where $\alpha$ is constant. Rewriting the point reactor equations in terms of $N(t)$ yields

$$
\Lambda \frac{d N}{d t}=(\rho-\beta) N+\sum \lambda_{i} C_{i}+S
$$

and

$$
\frac{d C_{i}}{d t}=\beta_{i} N-\lambda_{i} C_{i},
$$

where we have defined the parameters $C_{j}$ and $S$ by 


$$
C_{i}=\frac{\Lambda}{\alpha} C_{i} \text { and } S=\frac{\Lambda}{\alpha} q
$$

For either an IKRD or an IKRRI experiment the reactor is initially in a slightly subcritical equilibrium state. Designating that initial state by the subscript 0 and noting that the time derivatives in Eqs. $(A-5)$ and $(A-6)$ vanish, it then follows from those equations that

$$
\left(\rho_{0}-\beta\right) N_{0}+\sum \lambda_{i} C_{i 0}+S=0
$$

and

$$
0=\beta_{i} N_{0}-\lambda_{i} C_{i 0}=0
$$

Solving for $C_{j 0}$ and $S$ gives

$$
C_{i 0}=\frac{B_{i}}{\lambda_{i}} N_{0}
$$

and

$$
S=-\rho_{0} N_{0}
$$

Equations $(A-9)$ and $(A-10)$ comprise important information for a direct kinetics algorithm.

To obtain direct kinetics equations it is convenient and sufficiently accurate to employ the zero lifetime approximation which holds when

$$
\Lambda\left|\frac{d N}{d t}\right| \ll|(\rho-\beta) N|
$$

Qualitatively, this requires that $\Lambda$ be quite small, that $\rho$ be less than and not too near $\beta$, and that no fast transients occur. These conditions are easily met by the IKRD and IKRRI experiments proposed for low power physics tests in the FTR, for example. In this approximation, Eqs. $(A-5)$ and $(A-6)$ become 


$$
0=(\rho-\beta) N+\sum \lambda_{i} C_{i}+S
$$

and

$$
\frac{d C_{i}}{d t}=\beta_{i} N-\lambda_{i} C_{i} .
$$

Solving Eq. $(A-11)$ for $N(t)$ gives

$$
N(t)=\frac{S+\sum \lambda_{i} C_{j}(t)}{\beta-\rho(t)} .
$$

Now in direct kinetics $\rho(t)$ is known, so according to Eq. $(A-13), N(t)$ can be generated if the $C_{j}(t)$ can be determined.

To obtain the $C_{i}(t)$, Eq. $(A-12)$ is rewritten as

$$
\frac{d}{d t}\left[e^{\lambda_{i} t} c_{i}(t)\right]=e^{\lambda_{i} t}{ }_{\beta_{j}} N(t) .
$$

Integrating from $t$ to $t+\delta t$ results in

$$
c_{j}(t+\delta t)=C_{j}(t) e^{-\lambda_{j} \delta t}+\beta_{j} e^{-\lambda_{j}(t+\delta t)} \int_{t}^{t+\delta t} e^{\lambda_{i} t^{\prime}} N\left(t^{\prime}\right) d t^{\prime} .
$$

If $\delta t$ is chosen to be small enough so that $N\left(t^{\prime}\right)$ varies little over the interval of integration then $N\left(t^{\prime}\right)$ can be approximated by $N(t)$ and slipped out of the integral. The integral can then be performed yielding 


$$
C_{j}(t+\delta t)=C_{i}(t) e^{-\lambda_{j} \delta t}+\frac{\bar{\beta}_{i}}{\lambda_{i}} N(t)\left[1-e^{-\lambda_{j} \delta t}\right] .
$$

Al1 the ingredients of the algorithm now are present. Equations (A-9) and $(A-10)$ comprise the starting equations. Equation (A-16) is next employed to generate the first nonequilibrium $C_{j}$ which is then employed in Eq. $(A-13)$ to generate the subsequent $N$ value. The loop through Eqs. $(A-16)$ and $A-13)$ is then continued until the desired $N(t)$ profile is generated. Thus the necessary equations for the direct kinetics algorithm, gathered together, are

$$
\begin{gathered}
C_{i 0}=\frac{\beta_{i}}{\lambda_{i}} N_{0} \\
S=-\rho_{0} N_{0} \\
C_{i}(t+\delta t)=C_{i}(t) e^{-\lambda_{i} \delta t}+\frac{\beta_{i}}{\lambda_{i}} N(t)\left[1-e^{-\lambda_{j} \delta t}\right] \\
N(t+\delta t)=\frac{S+\sum \lambda_{i} C_{j}(t+\delta t)}{\beta-\rho(t+\delta t)} .
\end{gathered}
$$

In both appendices $B$ and $C$ the algorithm entitled, DRKIN, is based on these equations. It is worth noting that in that subroutine the experimental time interval for counting is called, DT, while the calculational time interval corresponding to $\delta \mathrm{t}$ is called $\mathrm{TL}$, which equals DT divided by an integer chosen to legitimatize the approximation used to obtain Eq. (A-16).

Equations $(A-11)$ and $(A-12)$ can also provide the basis for the inverse kinetics algorithm. However, to allow for the possibility of perceiving some transient behavior, it was decided to employ the point reactor equations in their less approximate form using Eq. (A-5) rather than (A-11). Recall Eq. (A-15), and to allow for a more rapid time variation, assume. 


$$
N\left(t^{\prime}\right)=N(t) e^{-\gamma\left(t^{\prime}-t\right)}
$$

so that after integration, Eq. $(A-15)$ becomes

$$
C_{i}(t+\Delta t)=C_{i}(t) e^{-\lambda} e^{\delta t}+\frac{\beta_{i}}{\lambda_{i}-\gamma} N(t+\delta t)-N(t) e^{-\lambda} \delta t
$$

with $\gamma(t)=\frac{1}{\delta t} \ln \frac{N(t)}{N(t+\delta t)}$.

Combining Eqs. $(A-5)$ and $(A-17)$ results in the form

$$
-\gamma \Lambda N(t)=[\rho(t)-\beta] N(t)+\sum \lambda_{i} C_{i}(t)+S
$$

which when solved for $p(t)$ gives

$$
\rho(t)=\beta-\gamma(t) \Lambda-\frac{\sum \lambda_{i} C_{i}(t)+S}{N(t)} .
$$

Gathering together the equations needed for the inverse kinetics subroutine gives the 1 ist

$$
\begin{gathered}
C_{i 0}=\frac{\beta_{i}}{\lambda_{i}} N_{0} \\
\rho_{0}=-S / N_{0} \\
C_{i}(t+\delta t)=C_{i}(t) e^{-\lambda_{i} \frac{\mu}{\delta t}}+\frac{\beta_{i}}{\lambda_{i}^{-\gamma(t)}}\left[N(t+\delta t)-N(t) e^{\left.-\lambda_{i} \delta t\right]}\right]
\end{gathered}
$$




$$
\rho(t)=\beta-\Lambda \gamma(t)-\frac{\sum^{\lambda_{i} C_{i}(t)+S}}{N(t)}
$$

with $\gamma(t)=\frac{1}{\delta t} \ln [N(t) / N(t+\delta t)]$.

These equations are the basis for the subroutine called RHOPRO appearing in Appendix $C$. 


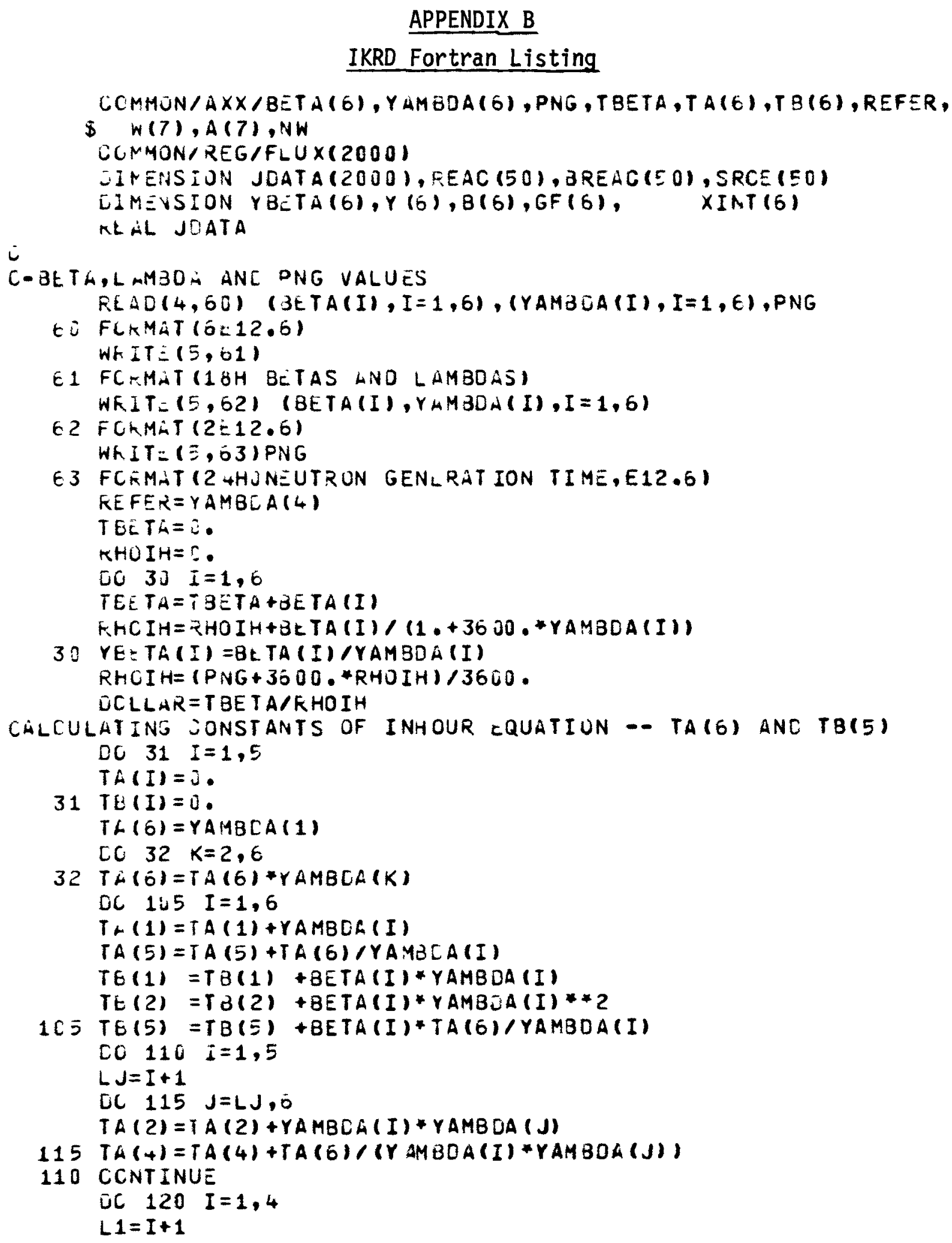




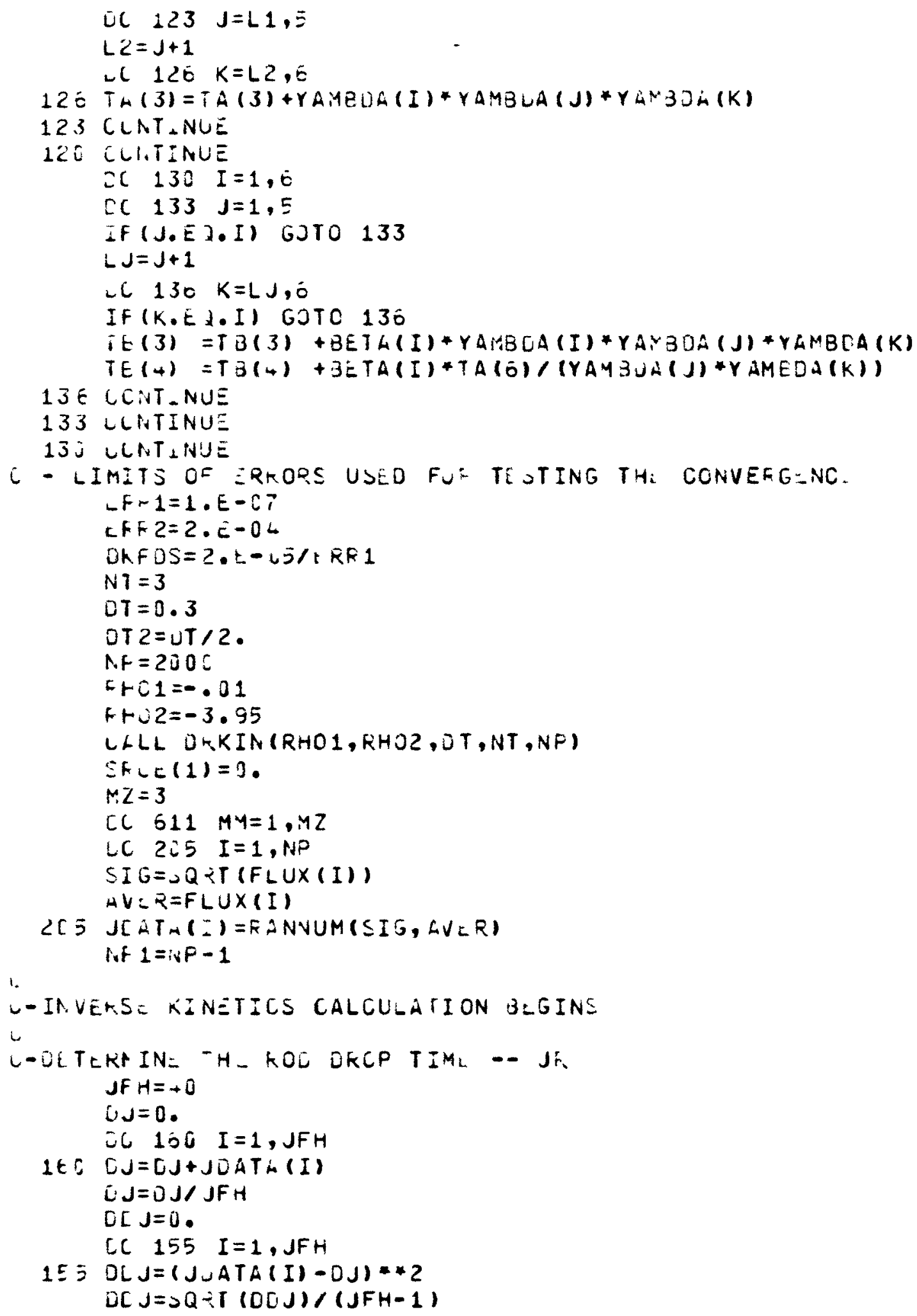




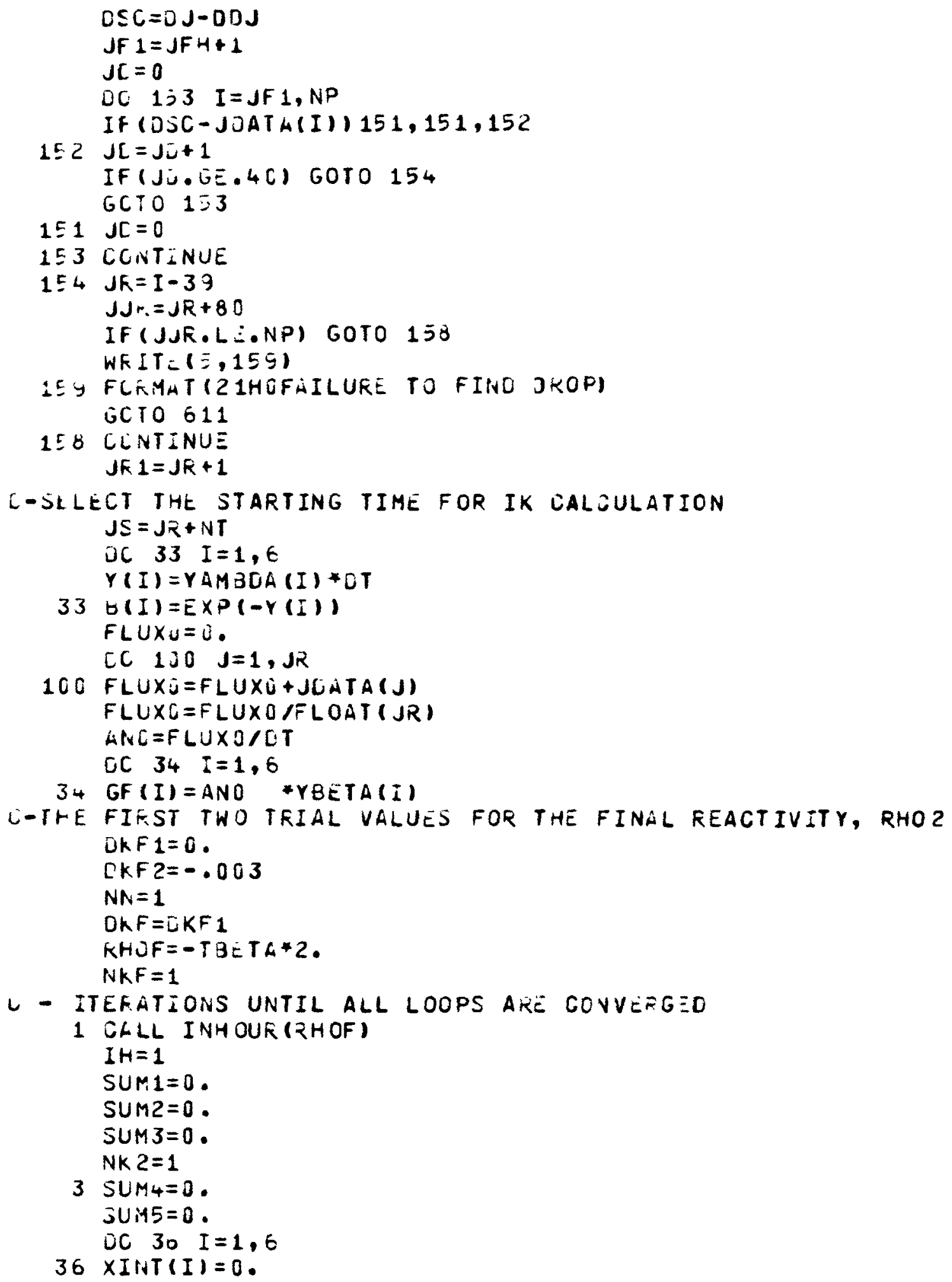




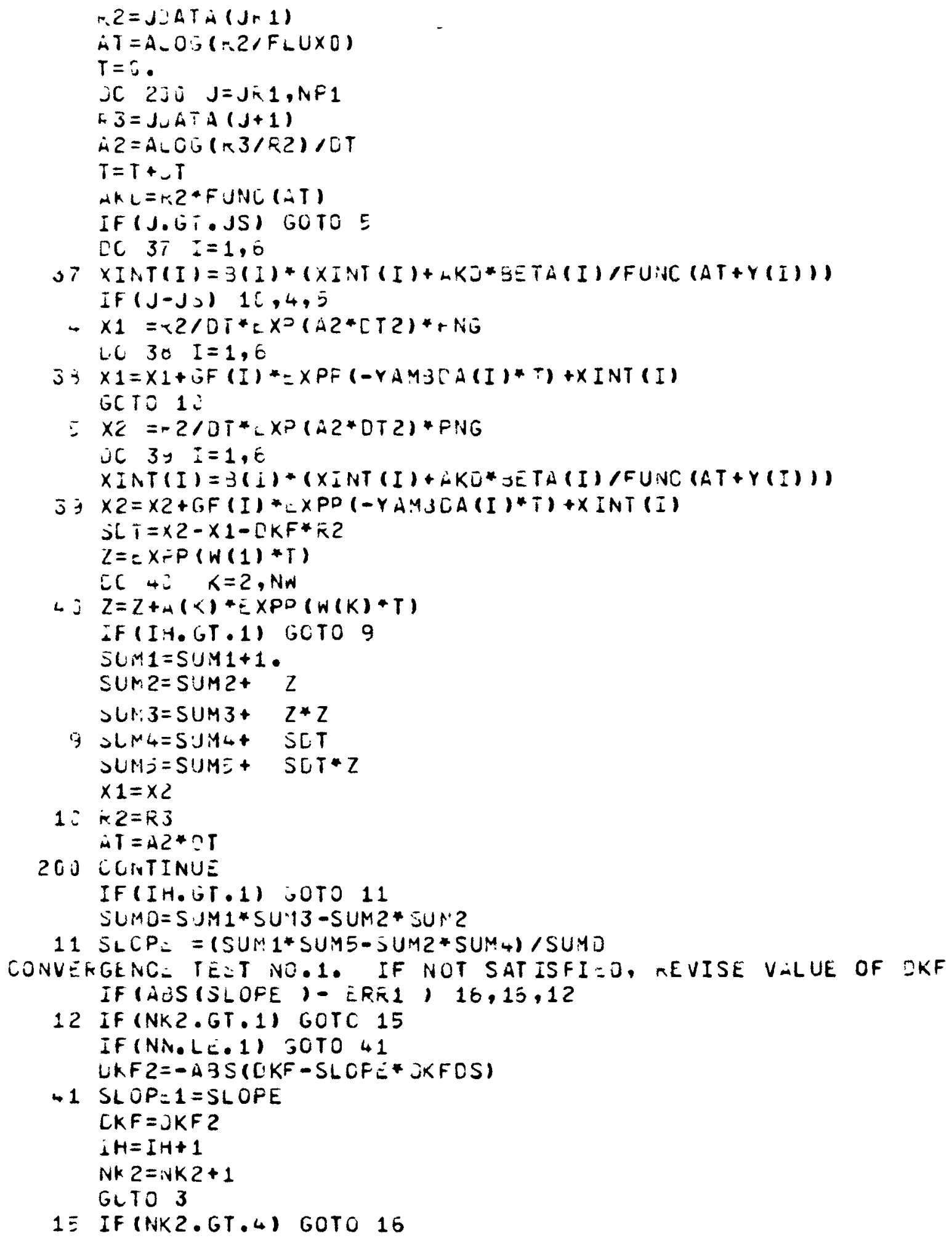

11 SLCP $=$ = (SUM $1 *$ SUMS- SUM2*SUM 4$) /$ SUMD

CONVEFGENC= TE:T NO.1. IF NOT SATISFI 0 , REVISE VALUE OF DKF IF (AOSS (SLOFE) - ERR̃1, $16,15,12$

12 IF (NK2.GT.1) GOTC 15

IF (NN.LE. 1$)$ JOTO 41 UKF $2=-\triangle 3 S(C K F-S L C F E * J K F O S)$

-1 SLOP $=1=S L O F E$

CKF $=J K F 2$

$I H=I H+1$

NK2 $=i N K 2+1$

GLTO 3

$1 \equiv$ IF (NK2.GT.4) GOTO 16 
IF (SLURE EEQ.SLOPE1) GUTO 16

$D K F O S=(O K F-D K F 1) /(S L O P .-S L O P L 1)$

CKF $1=[K F$

$S L C P=1=S L O P E$

$C K F=J K F-S L O P E * D K F D S$

$N K 2=N K 2+1$

UCTO 3

15 KHCFU $=$ UKF

$N N_{*}=2$

$\angle E=($ KHUFC-RHOF $) / K H O F C$

LONVERGENCE TEST NO. 2. IF NOT SATISFIED, REVISE VALUE OF RHOF IF (A3S (EB)-EKK 2) $20,20,19$

19 IF (NKF. GT $\rightarrow)$ GOTO 20

i $K F=N K F+1$

RTOF $=$ RHOFC

GCTO 1

23 SLTCHL $=$ (SUM 3* SUML-SUMZ* SUME) /SUYD

FHU1=-\UTCAL/ (FLUXO*KHUIH)

FHU2 $=D K F /$ R.HOIH

IK.HO=RHOZ-RHU1

$S S S=-H O 1 / D O L L A F$

$S E \rightarrow=K H O 2 / D C L L A=$

WKIT $=(5,020) \mathrm{MM}$

O20 FORMAT ("ORUN NUMBER IS", I5)

WFIT_ $(\equiv, 021) \quad 5 S 3, S 5+$

D21 FCFMAT ("OINITIAL AND FINAL ?EACTIVITIES ARE", 2E15.6)

OKLAE (MM) $=$ RHOI

REAC $(M Y)=$ KHC2

BF HO1 $=$ J.

FFHO1=0.

CC $610 \quad I=1, M M$

BKHO1 $=3 R H O 1+3 K E A C(I)$

E1O FRHO1 $=F R H O 1+\bar{X} E A C$ (I)

BF HO1 $=3 R H O 1 / A M / C O L L A \bar{R}$

$F K H O 1=F R H O 1 / M M / D O L L A F$

$S K C E(M M+1)=S Z C E(M M)+S D T C A L$

011 CCNTINUE

SRCC $=S K C E(M Z+1) / F L O A T(M Z)$

WFIT: $(5,7+5)$ SRCC

745 FCFMAT (18HOAVERAGE SUUFCE IS, E 12.51

$B F E A U T=0$

KE LCT $=J$.

$C C$ O13 $M M=1, M Z$

OFEAUT $=3$ EACT + BREAC (MM)

613 REACT $=\angle E A C T+R E A C(M M)$

FEHOF = रूACT $1: 1 Z$

$B F H O=B \subseteq \equiv A C T / M Z$

STD $=U$.

STLEV $=0$. 


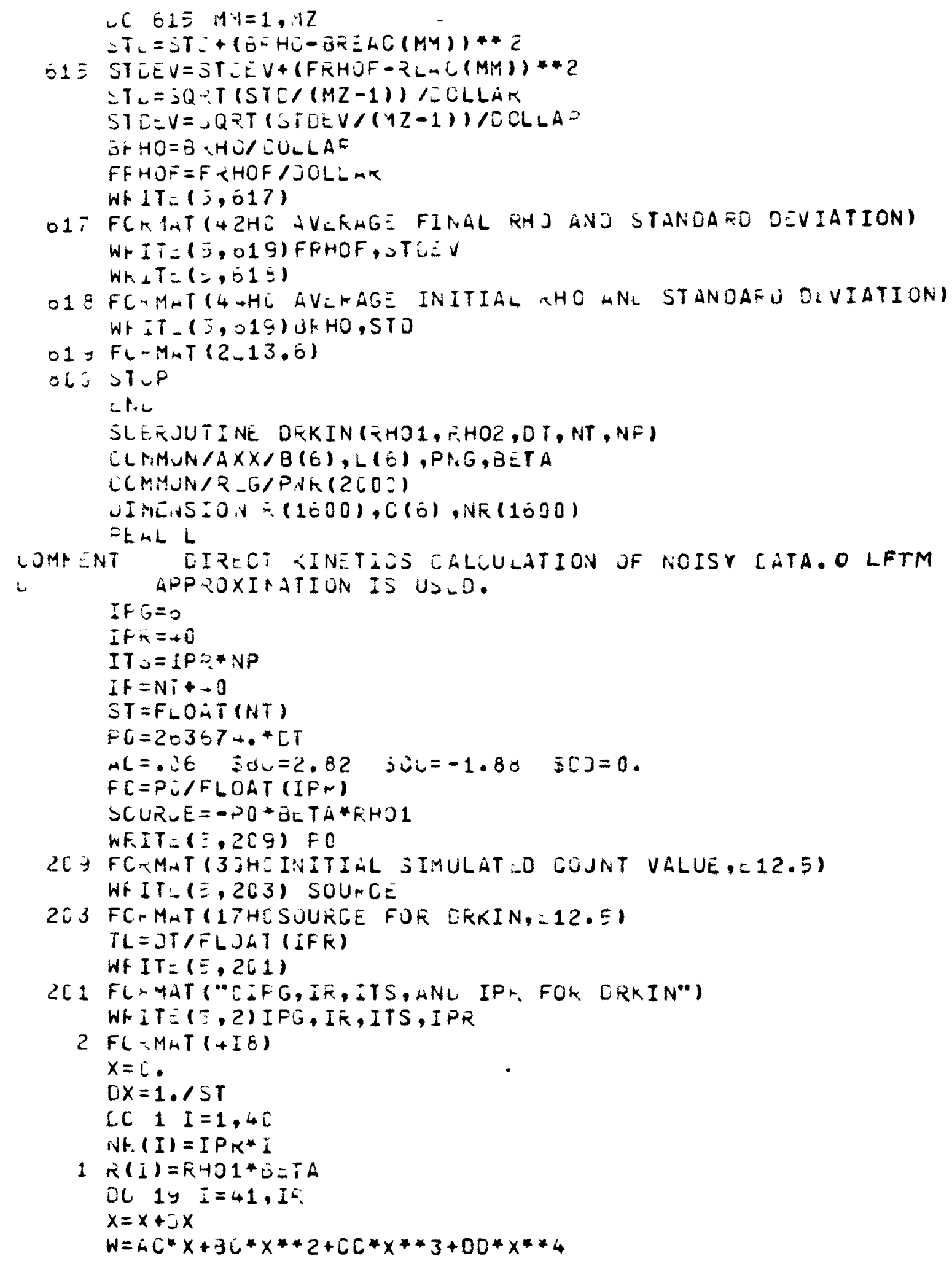




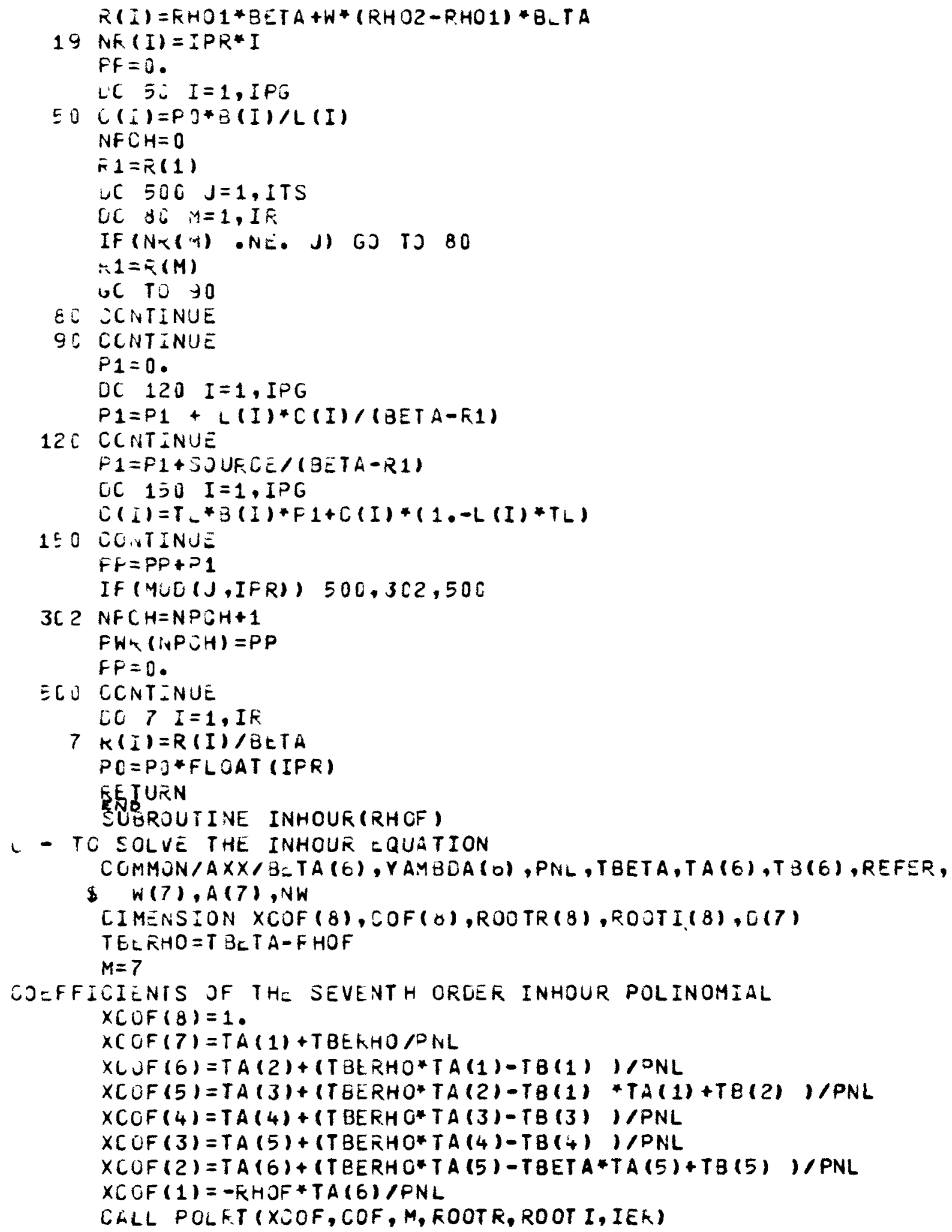




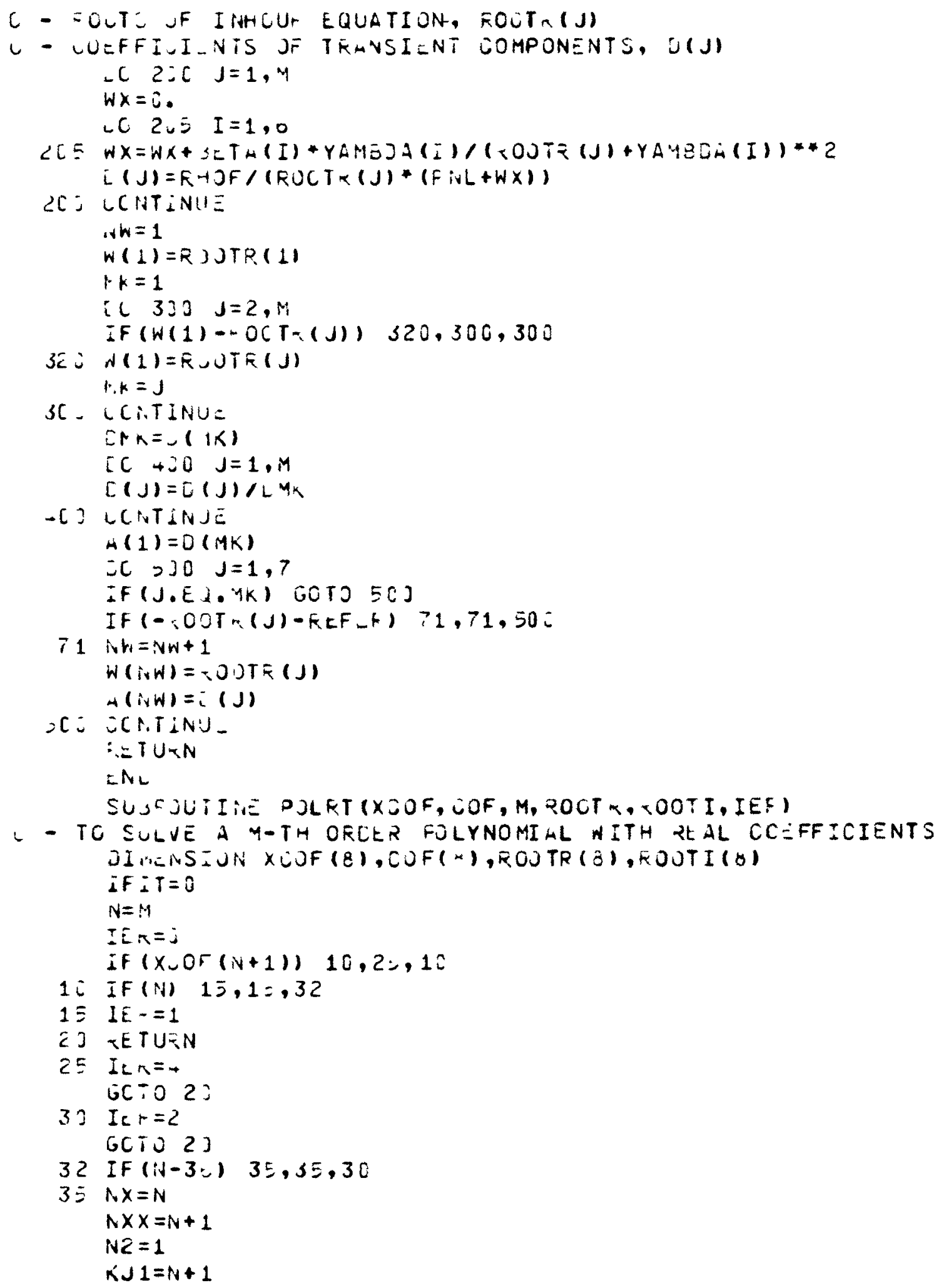




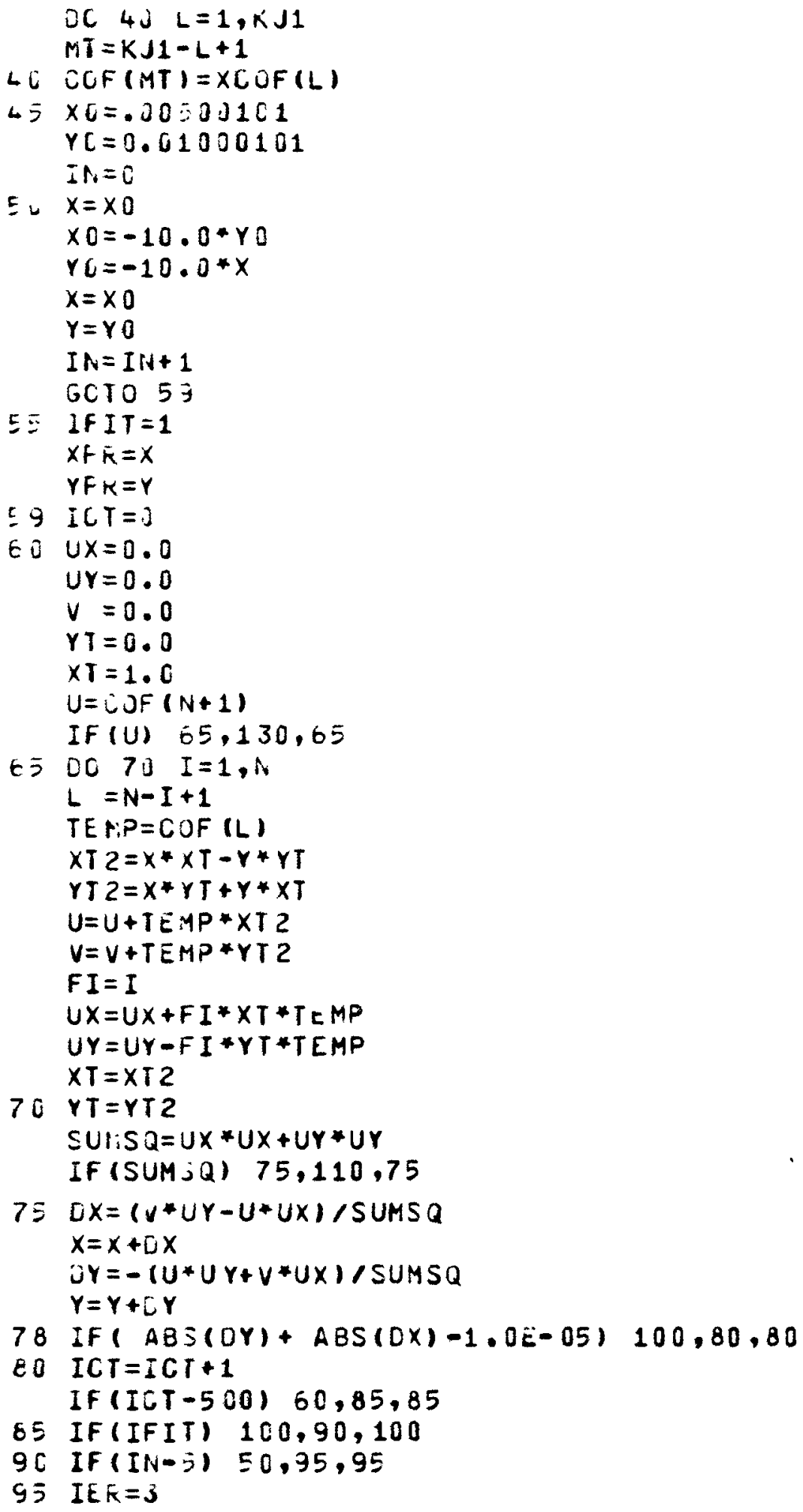


GCiO 23

$1 し=$ LC $1, \bar{L}=1, N \times X$

$M T=K J 1-L+1$

$T E P P=X \backsim J F(N T)$

$X L C F(M T)=C \cup F(L)$

$10 \equiv$ jCF $(L)=T \cdot M=$

$\sum T=M r=i N$

$n=i v X$

ii $X=I T E \because P$

If (IFIT) $120,55,120$

11 if IF (IFI') $115,50,115$

$11 ; x=X P$

$r=Y D_{r}$

12: if $I T=\bar{U}$

122 If $\left(A 5 j(r)-1.0=-4^{*}\right.$ AES $\left.(x)\right) \quad 135,125,125$

$12 \equiv H L+H M=X+X$

SU: Su $=x * x+y * y$

$N=N-2$

GCTO $14 \mathrm{~J}$

10: $x=C \ldots$

$N x=14 x-1$

N $x \times=\operatorname{in} x \times-1$

$132 Y=i \cdot i$

SUAS $\alpha=0 . ?$

$\dot{A L F H}=X$

$N=N-1$

$1<3 \cup(F(2)=03 F(2)+\lambda L F M A * C J F(1)$

$145 C C \quad 1 ; 0 \quad L=2, N$

15. $C C F(L+1)=C O F(L+1)+N L=H A * C O F(L)-3 U M S Q * C J F(L-1)$

$155 K C=T I(v 2)=r$

$\therefore(C T-(\sqrt{2})=X$

$N 2=N 2+1$

IF $(S U M \triangle Q) 163,10 \pm, 100$

IE: $r=-r$

$S(H S)=j \cdot 0$

GCTO $1=\overline{5}$

1t: IF (N) $20,26,+5$

LAC

FUNCTI IN FUNS $(X A)$

LALLJLATES X/(EXP(X)-1.) FCF PROPOS=O ALGORITHM

$X=X A$

$X E=A 3 S(X)$

If $(x=-24,3) 2,2,1$

1 I $F(x) 3,3,4$

3 FUNE $=-x$

SETUAN

- FUNi $=X / E X P(X)$

KETUKN

2 If $(x 5-.2) 6,6,5$ 
5 FUNC $=X /(E X F(X)-1 \cdot)$

RETURN

- FUNC $=1 .-x * 1.5-x * 1.083333333333-(x * x) *(.0013888688869$

$\$-.00003306878307 *(x * x))) 1$

RE TURN

ENC

FUNCTILN EXPP (XA)

$i$ - TO AVOID UNDERFLCW (JR OVERFLOW) JALCULATIONS

IF $(X A+30,1,1,2$

1 EXPP $=0$.

RE TUKN

$2 \angle X P P=E X P(X A)$

KETUF.N

ENC

FUNCTION RANNUM(SIG, AVER)

C POLAL GEINERATION CF NOISY FLUX REF P.104 KNUTH

4 V $1=2$. $\because A N F(-1)-1$.

$V 2=2 . * A \cdot V(-1)-1$.

$S=V 1 * V 1+V 2 * V 2$

IF $10 . G E \cdot 1.1$ GOTO 4

RANNUM = AVEK+SIG*V1*SQET $(-2$ *ALOG $(S) / S)$

F.E TURN

ENC 


\title{
APPENDIX C
}

\author{
IKRRI Fortran Listing
}

PROGRAM IKRRIIINPUT . OUTPUT -TAPEA = INPUT , TAPE 5=OUTPUTI

COMMON/CSQ/RR HO (1800),RIA (1800) NT,B11,B12,B13,R21.B22,

*B32, B33,B23,B 31

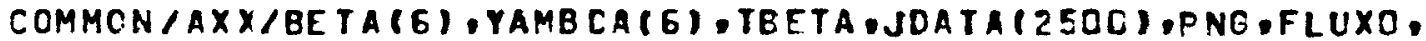

* NP.DT.RE AC $(2500$ ) . NP1, RHCIH

COMMON/REG/AC, BC,CC,OC, X5, X6, X7, X8

DIMENSION STOV(1800),PAC(50),PBC (50),PCC (50),POD(50)

CIRENSION AK( $3 C), B K(3 C), C K(3 C), 0 K(3 C)$, FLUR (2500), FLUX (2500)

RFAL I11,I12,I13,I?1,I22,I23,I31,I32,I33

PTAL JCATA

C-IETA.LAMSDA AND PNG VALUES

RE AC( 4,60) (BETA(I),I=1,6), YAMEOA (I),I=1,E),PNG

6] FORMAT (6E12.6)

WRITT $(5,61)$

G1 FORMAT(13H BETAS AND LAMBDAS)

WFITE (5,E 2$)$ (BETA(I), YAMBDA $(I), I=1,6)$

62 FORMAT (2E12.6)

WEITE (5,E 3 IPNC

63 FORMAT(24HDNEUTRON GENERATION TIYE.E12.6)

TPETA $=0$.

RH OIH=0.

CC $30 \quad I=1,6$

TBETA=TBETA+BETAPI)

$3 C$ FHOIH $=R H O I H+B E T A(I) /(1 .+36(C . * Y A M B D A(I))$

RHOTH= (PNG+3600. *RHOTH)/3600.

DOLLAR $=$ TBETA/RHCIH

C DT IS THE TIME INCREMENT FOR EACH COUNTRATE VALUE.

D T $=0.3$

C NP IS THE TOTAL NUMBER OF COUNTRATE VALUES TO BE ANALYZED. $N F=2000$ $N P 1=N P-1$

CCMPENI. NT IS TIME INCREMENTS TAKEN UP BY ACTUAL ROD MOTICN. $N T=800$ WRTTE (5.72) NT

72 FORMAT (31HOTIME INCREMENTS FOR ROD MOTION,I5)

C IFF IS THE NUMBER OF INDEPENDENT DETECTORS. $I P P=3$

$K J K=8$

DO $200 \quad I=1, N T$

2OC RTN(I)=FLOATIII/FLCATINT)

$X 1=0$.

$x_{2}=0$.

$\times 3=0$.

$x_{4}=0$.

$\times 5=0$.

$x 6=0$.

$\times 7=0$. 


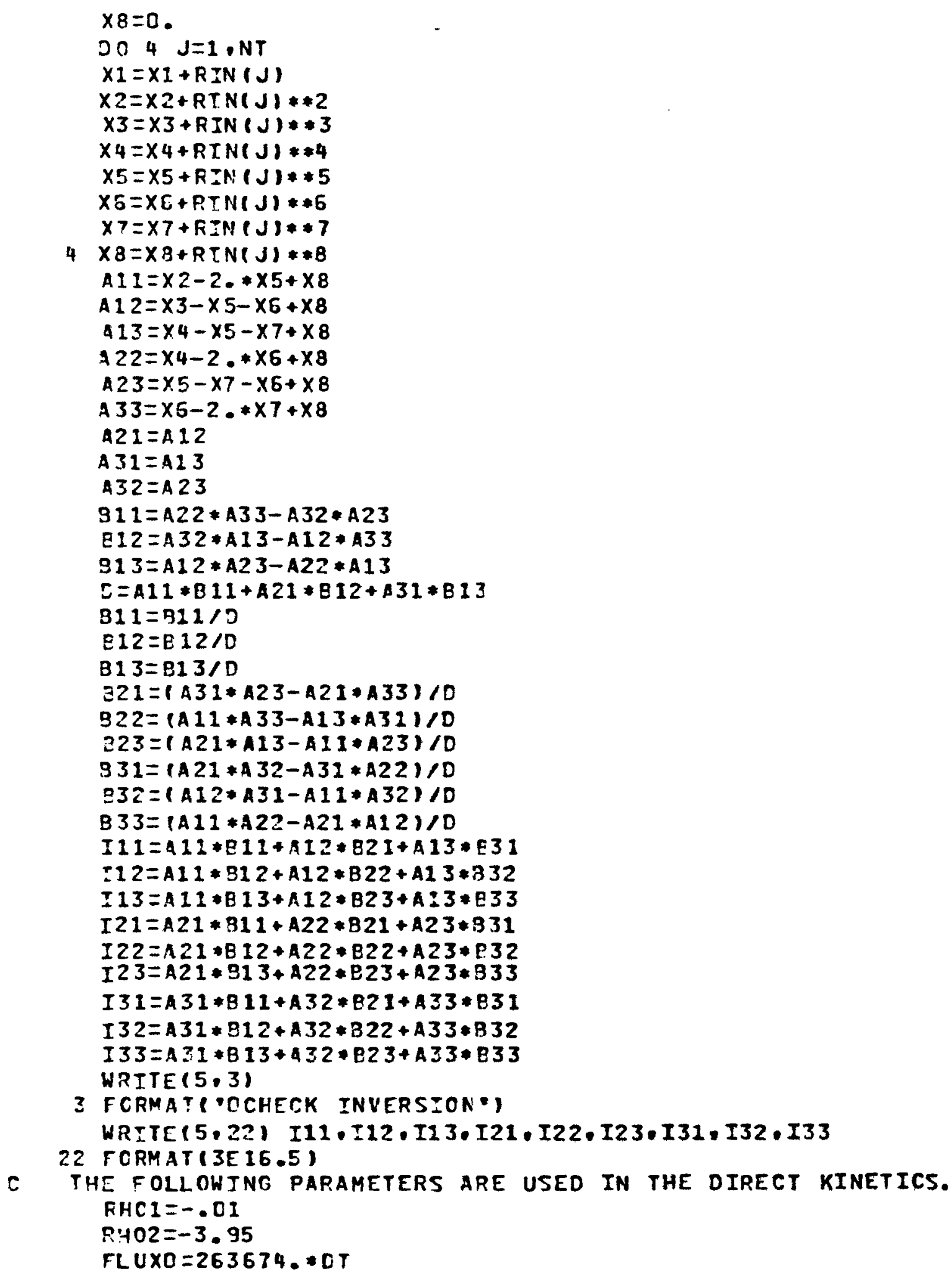




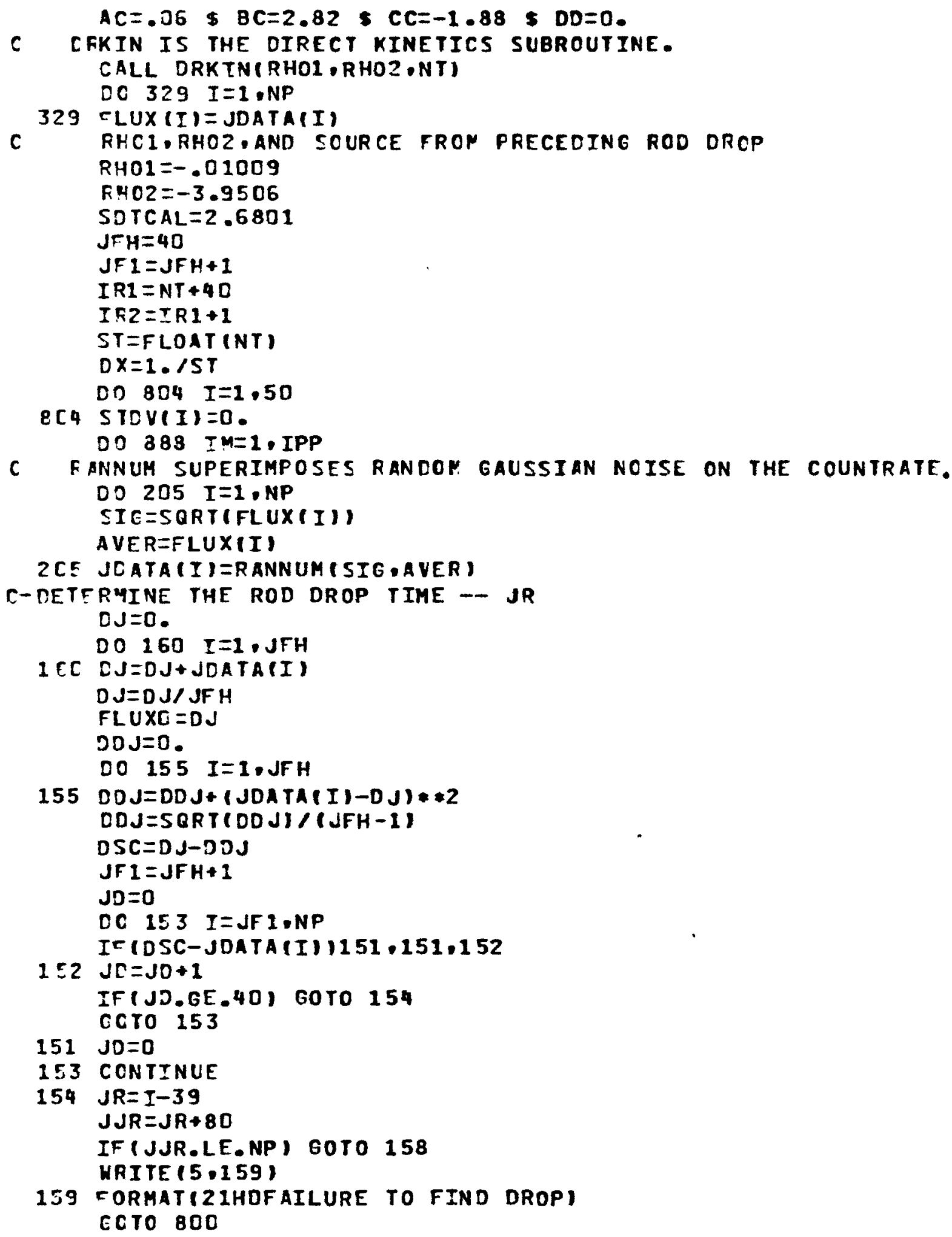


158 CONTTNUE

WRITE (5.501) JR

501 FORMATII 3HOFIPST TRY AT JR IS.I5)

FLI $1=0$.

$F L 2=n$.

$J R 3=J R-2 C$

DO $301 \quad I=J R 3, J R$

$F L 1=F L 1+J O A T A(I)$

$331 F L 2=F L 2+J D A T A(I+20)$

$F L I=F L 1 / 20$.

$F L 2=F L 2 / 20$.

$J R=J R-I N T(40 . /(F L I-F L 2) * S Q R T(F L 1))$

WRITE 5.1$)$ JR

1 FORMAT(ISHOAD JUSTEC JR IS.I5)

$J R 1=J R+1$

CCMMENT. RHOPRO IS THE INVERSE KINETICS ROUTINE.

COMMENT. SOTCAL IS THE EFFECTIVE SOURCE.

CALL RHOPRO (SCTCAL)

DO $201 \mathrm{~J}=1, \mathrm{NT}$

2 QI RRHO(J)=(PEAC $(J+J R)-R E A C(N R)) /(R H O 2-R H O 1) / D O L L A R$

COMMF"T. LSG SMOOTHS RRHO.

CALL LSO

WRTTE (5.221)

221 FCRMAT( OFIT COEFFICIENTS OFIRST THRCUGH FOURTH OROER') WRTIEI5,222, AC,BC,CC,DD

222 FORMAT(4E12.5)

$A^{n}=A C \quad \$ B G=3 C \quad \$ C G=C C \quad \$ D E=D D$

$A K(I M)=A C \quad \$ B K(I M)=B C \quad S C K(I M)=C C \quad \$ D K(I M)=D D$

DO $204 \quad T=1, N T$

204 RRHO(I)=AC*RIN $(I)+B C * R I N(I) * 2+C C * R I N(I) * 3+D O * R I N(I) * 4$

COMMTNT. NOH RRHO IS THE SMOOTYED RELATIVE ROD WORTH.

CC $22.3 I=1, N T$

223 RRHO(I) $=$ RPHO $(I) *(R H O 2-R H O I)$

WFITE (5,224)

224 FORMATI'DROD WORTH ARRAY')

WRITE (5.225)(RRHO(I), I=I,NT,KJK)

225 FORMAT (1OE12.5)

CALL DËKINIRHOI.RHCZ,NTI

CO $328 \quad I=1$. NP

$32 E$ FLUB(I)=JDATAII)

$M Z=30$

$M Z 1=M Z-1$

$D O 199 M M=1, M Z$

$00172 \quad I=1, N P$

SIE $=S Q R T(F L U B(I))$

AVER=FLUB(I)

172 JOATA (I) =RANNUM (SIE, AVER)

C-DETERMINE THE ROD DROP TIME -- JR $J F H=40$ 


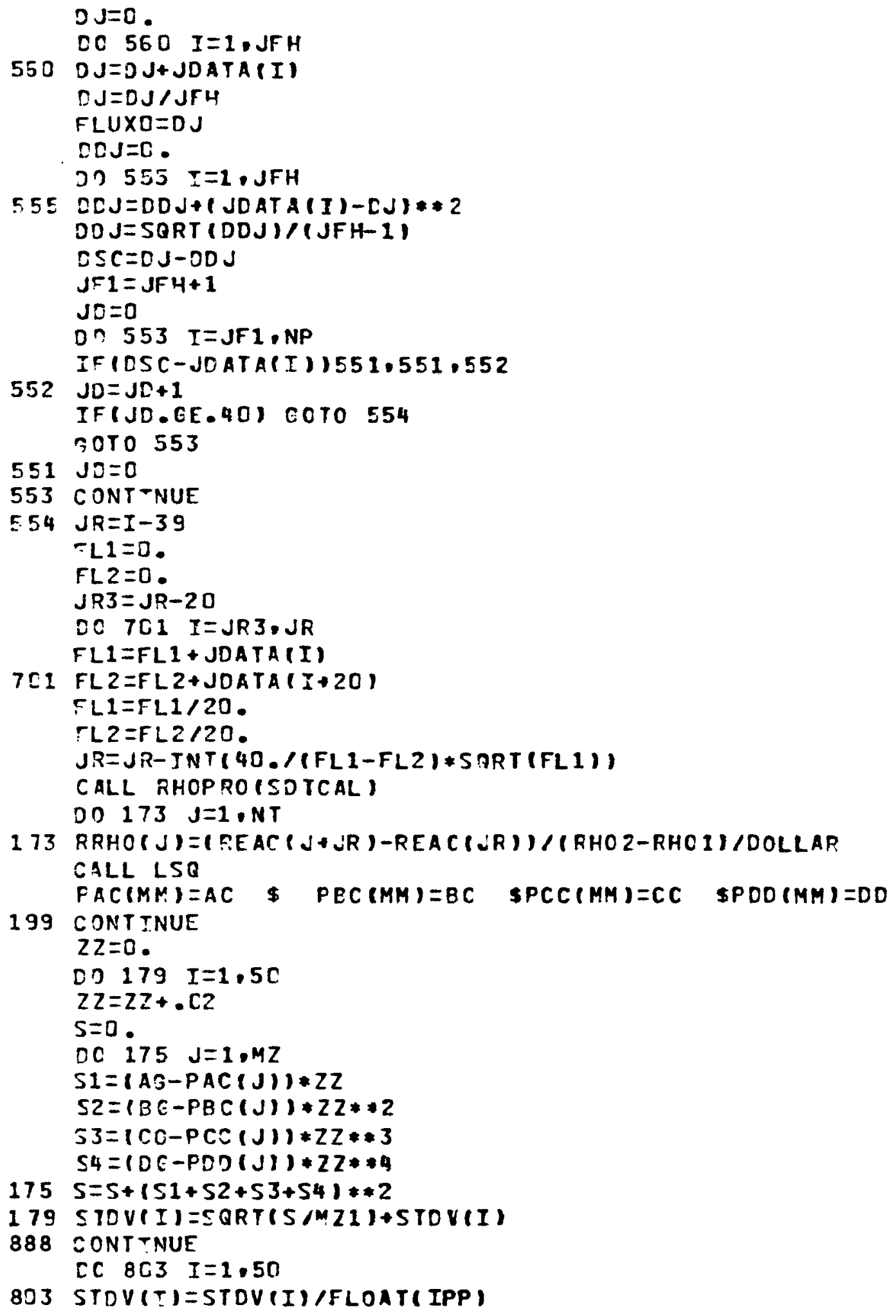


KPITE $(5.801)$

831 TORMATI OESTIMATED STANOARD OEVIATIONS')

WFITC $(5,802)(S T D V(I), I=I, 50)$

SO2 FORMAT (2E14.6)

$A C=0 . \quad \$ B C=C . \quad \$ C C=C . \quad \$ C C=C$.

DO $1 \mathrm{C}$ IM=1,IPP

$A C=A C+A K(T M)$

$B C=B C+B K(T M)$

$C C=C C+C K\left(I^{M}\right)$

15 $D D=D T+D K(I M)$

$A C=A C / I F P$

$B C=3 C / I P P$

$C C=C C / I P P$

$D D=D D / I P P$

WFITE(5.302)

332 FORMATI'OAVERAGE FIT COEFFICIENTS')

WRITE $(5,303$ IAC,BC,CC,DD

303 FORMAT ( 4 E12.5)

CC $307 \quad I=1, N T$

$R R H O(I)=A C * R I N(I)+B C * R I N(I) * 2+C C * R I N(I) * 3+D D * R I N(I) * 4$

307 RRHC (I) $=R R H O(I) *(R H O Z-R H C I)$

NRITE $(5,309)$

ICE FORMATI OAVEPAGE EXPERIMENTAL REACTIVITY AFRAY"I

HRITE (5.311) (RRHO(I), I=1,NT.KJK)

311 FORMAT(1OE12.5)

800 STOP

CNC

SUURUJTIVE RHJFRU(SCTLAL)

CALCULATES REACTIVITY FEOFILE

SOMYON/AXX/3(O), Y (E) , BETA, F(2ESO), RNG,POW, KK, OT,

* XHO(2500), NP1, RIH

UIMER.SIOP C $C(5)$

$S=S O T C A L$

$M=K K-1$

DO $1: I=1,0$

1? $C(I)=B(I) * F O W / Y(I)$

OC $1 \quad I=1, \mathrm{~N}$

IF $((A B E(F(I) / D(I+1))-1.) . E 0 . s$.$) GOTO 2$

$G=A \operatorname{LOG}(D(I) / F(I+1)) / 3 T$

GOTO?

? $G=:$.

- CONTINUE

$T_{1}=3$.

[O $\& J=1,0$

$C(J)=C(J) * E X P(-Y(J) *[T)+3(J) /(Y(J)-i) *$

$1(P(I+1)-F(I)+\vec{E} \times P(-Y(J)+O T))$

$4 T 1=T 1+C(J) * Y(J)$

1 RHO $(I+1)=3 E T A-G * P N G-(S+T 1) / P(I+1)$

FHC $(1)=-S / F O W$ 


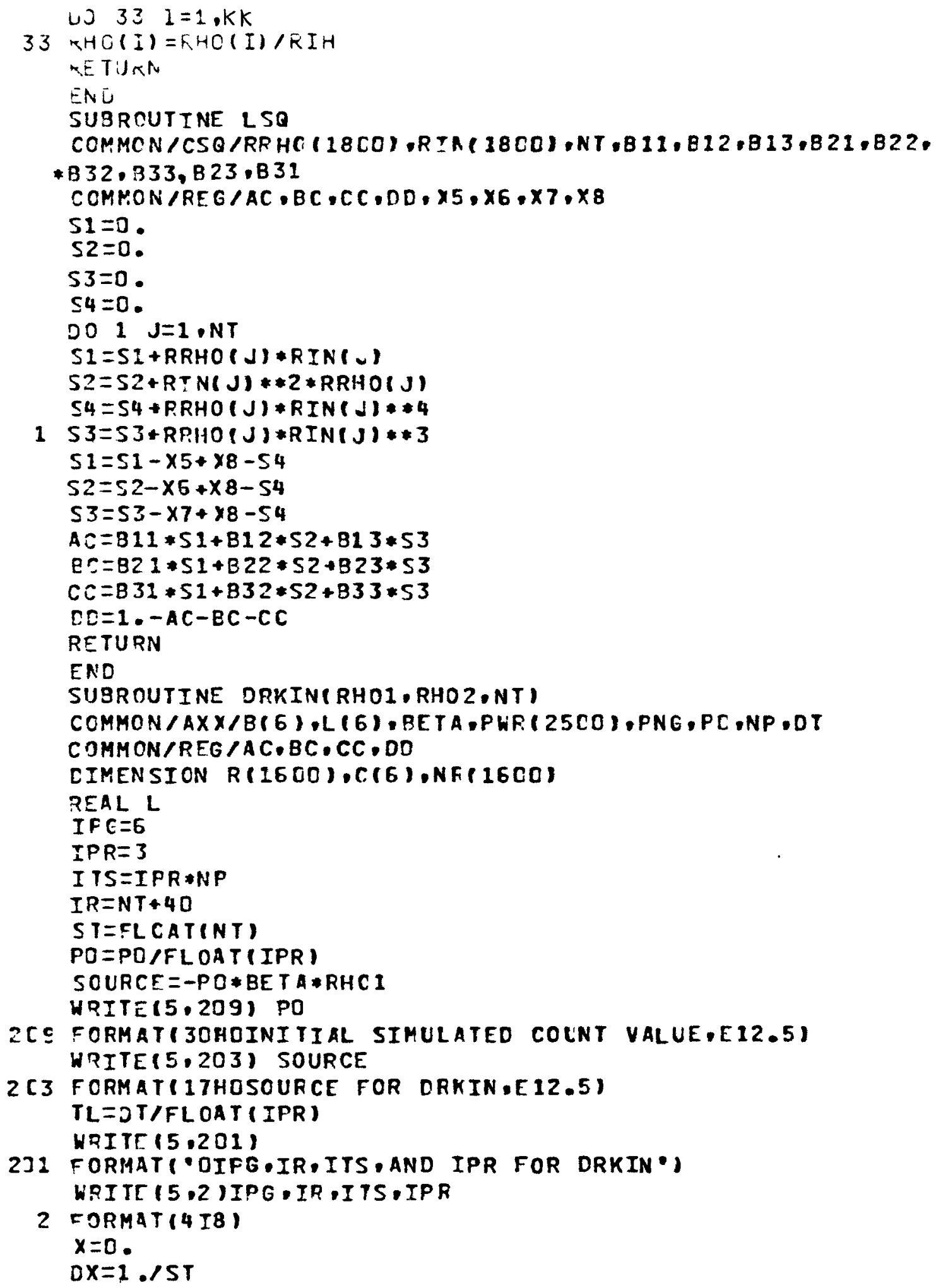


CC $1 \quad I=1,40$

NR (I) $=T P R * I$

$1 R(I)=R H O I * B E T A$

CO $19 T=41$,IR

$X=X+D X$

$W=A C * X+B C * X * 2+C C * X * 3+D D * X * * 4$

$R(I)=R H O 1 * B E T A+H *(R H O Z-R H C 1) * B E T A$

$19 N R(I)=P P R * I$

$P F=0$.

DO $50 \quad T=1$. IPG

$50 C(I)=P O * P(I) / L(I)$

NPCH $=0$

$R I=R(1)$

Oว $500 \mathrm{~J}=1$,ITS

CC $80 \quad M=1$, IR

IF(NR(M) -NE. J) GO TO 80

$R 1=R(M)$

30 TO 90

EC CONTINUE

30 CONTTNUE

$P 1=0$.

D) $120 \quad I=1, I P G$

$P I=P 1+L(I) * C(I) /(B E T A-F I)$

120 CONTINUE

$F I=P I+$ SOURCE ( $(E E T A-R I)$

DO $150 \quad T=1 . I P G$

$C(I)=T L * B(I) * P I+C(I) *(I--L(I) * T L)$

15J CONTINUE.

$F P=P F+P$ I

IF (MCD(J.IPR) 500.302 .500

$3 C 2 N P C H=N P C H+1$

$P H R(N P C H)=P P$

$F F=0$.

530 CONT TNUE

DO 7 I $=1 . I R$

$7 R(I)=R(I) / B E T A$

$F O=P C * F L O A T(I P R)$

RETURN

ENC

EUNCTION RANNUM(SIG, AVER)

C FCLAR GENERATION OF NOISY FLUX REF P.IO4 KNUTH

$4 V 1=2$. RANF $(-1)-1$.

$V 2=2 * R A N F(-1)-1$.

$S=V 1 * V 1+V 2 * V 2$

IF (S.EE.1.) GOTO 4

RANNUM =A VER+SIG*VI*SQRT $(-2$ **ALOG $(S) / S)$

RETLRN

END 


\section{DISTRIBUTION}

UC-79 Basic List (204)

UC-79d Physics (18)

UC-79e Reactor Core Systems

ERDA-RL (2)

A.G. Fremling

R.M. Poteat

ERDA-FFTFPO-RL

R.L. Ferguson

Westinghouse Hanford Company

(17)

R.A. Bennett

(2)

J.W. Daughtry

R.A. Harris

R.W. Harmsen

D.L. Johnson

T.A. Mangelsdorf

R.E. Peterson

R.A. Sevenich

(2)

G.A. Worth

Central Records and Files

(5)

Publications Services

(2) 